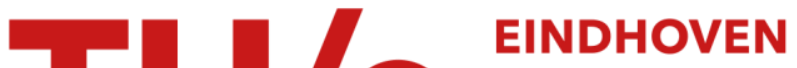 \\ UNIVERSITY OF \\ TECHNOLOGY
}

\section{Interaction of ice binding proteins with ice, water and ions}

\section{Citation for published version (APA):}

Oude Vrielink, A. S., Aloi, A., Olijve, L. L. C., \& Voets, I. K. (2016). Interaction of ice binding proteins with ice, water and ions. Biointerphases, 11(1), [018906]. https://doi.org/10.1116/1.4939462

DOI:

10.1116/1.4939462

Document status and date:

Published: 01/03/2016

\section{Document Version:}

Publisher's PDF, also known as Version of Record (includes final page, issue and volume numbers)

\section{Please check the document version of this publication:}

- A submitted manuscript is the version of the article upon submission and before peer-review. There can be important differences between the submitted version and the official published version of record. People interested in the research are advised to contact the author for the final version of the publication, or visit the $\mathrm{DOI}$ to the publisher's website.

- The final author version and the galley proof are versions of the publication after peer review.

- The final published version features the final layout of the paper including the volume, issue and page numbers.

Link to publication

\section{General rights}

Copyright and moral rights for the publications made accessible in the public portal are retained by the authors and/or other copyright owners and it is a condition of accessing publications that users recognise and abide by the legal requirements associated with these rights.

- Users may download and print one copy of any publication from the public portal for the purpose of private study or research.

- You may not further distribute the material or use it for any profit-making activity or commercial gain

- You may freely distribute the URL identifying the publication in the public portal.

If the publication is distributed under the terms of Article 25fa of the Dutch Copyright Act, indicated by the "Taverne" license above, please follow below link for the End User Agreement:

www.tue.nl/taverne

Take down policy

If you believe that this document breaches copyright please contact us at:

openaccess@tue.nl

providing details and we will investigate your claim. 


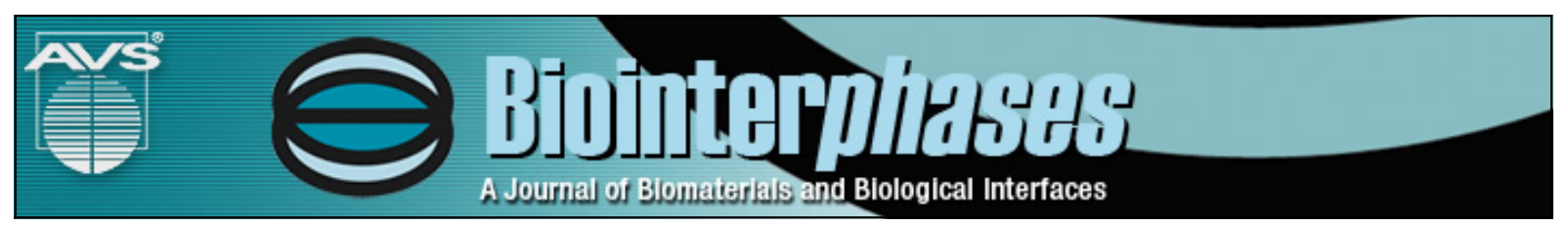

\section{Interaction of ice binding proteins with ice, water and ions}

Anneloes S. Oude Vrielink, Antonio Aloi, Luuk L. C. Olijve, and Ilja K. Voets

Citation: Biointerphases 11, 018906 (2016); doi: 10.1116/1.4939462

View online: http://dx.doi.org/10.1116/1.4939462

View Table of Contents: http://scitation.aip.org/content/avs/journal/bip/11/1?ver=pdfcov

Published by the AVS: Science \& Technology of Materials, Interfaces, and Processing

\section{Articles you may be interested in}

Explicit-water theory for the salt-specific effects and Hofmeister series in protein solutions

J. Chem. Phys. 144, 215101 (2016); 10.1063/1.4953067

The role of non-specific interactions in a patchy model of protein crystallization

J. Chem. Phys. 143, 194511 (2015); 10.1063/1.4935369

Computational study on ice growth inhibition of Antarctic bacterium antifreeze protein using coarse grained simulation

J. Chem. Phys. 140, 225101 (2014); 10.1063/1.4881895

Protein electron transfer: Dynamics and statistics

J. Chem. Phys. 139, 025102 (2013); 10.1063/1.4812788

Observation of high-temperature dynamic crossover in protein hydration water and its relation to reversible denaturation of lysozyme

J. Chem. Phys. 130, 135101 (2009); 10.1063/1.3081137 


\title{
Interaction of ice binding proteins with ice, water and ions
}

\author{
Anneloes S. Oude Vrielink, ${ }^{\text {a) }}$ Antonio Aloi, ${ }^{\text {a) }}$ and Luuk L. C. Olijve ${ }^{\text {a) }}$ \\ Institute for Complex Molecular Systems and Laboratory of Macromolecular and Organic Chemistry of \\ Department of Chemical Engineering and Chemistry, Eindhoven University of Technology, \\ Post Office Box 513, 5600 MD Eindhoven, The Netherlands \\ Ilja K. Voets ${ }^{\text {b) }}$ \\ Institute for Complex Molecular Systems, Laboratory of Macromolecular and Organic Chemistry of \\ Department of Chemical Engineering and Chemistry, and Laboratory of Physical Chemistry of Department of \\ Chemical Engineering and Chemistry, Eindhoven University of Technology, Post Office Box 513, \\ 5600 MD Eindhoven, The Netherlands
}

(Received 10 November 2015; accepted 21 December 2015; published 19 January 2016)

Ice binding proteins (IBPs) are produced by various cold-adapted organisms to protect their body tissues against freeze damage. First discovered in Antarctic fish living in shallow waters, IBPs were later found in insects, microorganisms, and plants. Despite great structural diversity, all IBPs adhere to growing ice crystals, which is essential for their extensive repertoire of biological functions. Some IBPs maintain liquid inclusions within ice or inhibit recrystallization of ice, while other types suppress freezing by blocking further ice growth. In contrast, ice nucleating proteins stimulate ice nucleation just below $0^{\circ} \mathrm{C}$. Despite huge commercial interest and major scientific breakthroughs, the precise working mechanism of IBPs has not yet been unraveled. In this review, the authors outline the state-of-the-art in experimental and theoretical IBP research and discuss future scientific challenges. The interaction of IBPs with ice, water and ions is examined, focusing in particular on ice growth inhibition mechanisms. (C) 2016 American Vacuum Society. [http://dx.doi.org/10.1116/1.4939462]

\section{INTRODUCTION}

In the 1950s, Scholander and coworkers set up a series of expeditions to the eastern Canadian arctic to study how Hebron Fjord fishes survive in their ice-laden, subzero habitats. $^{1,2}$ The team discovered that deep water fishes, which never encounter ice, permanently live in a supercooled state. But the coping mechanism of shallow water fishes remained unclear. These fishes did not freeze even in the presence of ice during the winter season. Roughly two decades later, DeVries et al. identified glycoproteins as the cryoprotective antifreezes in Antarctic fish. ${ }^{3-5} \mathrm{NaCl}$ and other osmolytes in the blood serum produced only $\sim 70 \%$ of the freezing-point depression necessary for survival. The remainder was attributed to a noncolligative effect caused by the antifreeze glycoproteins (AFGPs). ${ }^{4}$

Since the discovery of AFGPs in Trematomus borchgrevinki in 1969, ice-binding proteins (IBPs) have been isolated from various kingdoms of life. All IBPs modulate ice growth, which is essential for their extensive functional repertoire (Fig. 1). Well known is the IBP subclass of antifreeze (glyco)proteins $[\mathrm{AF}(\mathrm{G}) \mathrm{Ps}]$. These IBPs block growth of small, embryonic ice crystals in a narrow regime of subzero temperatures. Other IBPs structure ice, $, 7,7$ inhibit ice recrystallization, ${ }^{8,9}$ or promote ice adhesion. ${ }^{10,11}$ Ice nucleating proteins (INPs) stimulate ice nucleation at high subzero temperatures. ${ }^{12,13}$ The unique ability of IBPs to

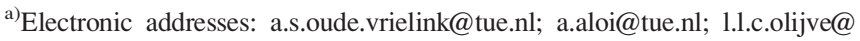
tue.nl

b) Author to whom correspondence should be addressed; electronic mail: i.voets@tue.nl
}

modify ice crystal growth also holds great promise for a range of application areas including food technology, materials science, and biomedicine. ${ }^{14-16}$

In this paper, we review major advances in the field of IBPs focusing in particular on recent experimental and theoretical studies aiming to elucidate how IBPs function. We first give an overview of the structure and function of IBPs, highlighting new developments in activity and ice-binding plane assays. Next, we describe what is known about the interaction of IBPs with ice, water, and ions. We conclude with a brief summary of the state-of-the-art and a perspective on future challenges in the field.

\section{BIOLOGICAL FUNCTION OF ICE-BINDING PROTEINS}

Ice-binding proteins have been isolated from fishes, plants, insects, and terrestrial arthropods, as well as microorganisms such as bacteria, fungi, and algae. These species can be classified as either freeze-avoiding or freeze-tolerant: the former prevent freezing as it is lethal, while the latter are able to survive it. ${ }^{12,13}$ Four different roles of IBPs in these cold-adapted organisms have been identified: antifreeze, ice recrystallization inhibition, ice structuring, and ice adhesion (Fig. 1). Furthermore, INPs stimulate ice nucleation just below $0^{\circ} \mathrm{C}$. When new IBPs are discovered, a series of experiments assaying for the various activities is carried out to confirm that the protein indeed acts as an IBP and binds ice. Optical microscopy is routinely used to study IBPinduced ice shaping and to determine the melting and freezing point of for example blood serum, hemolymph, or cell 

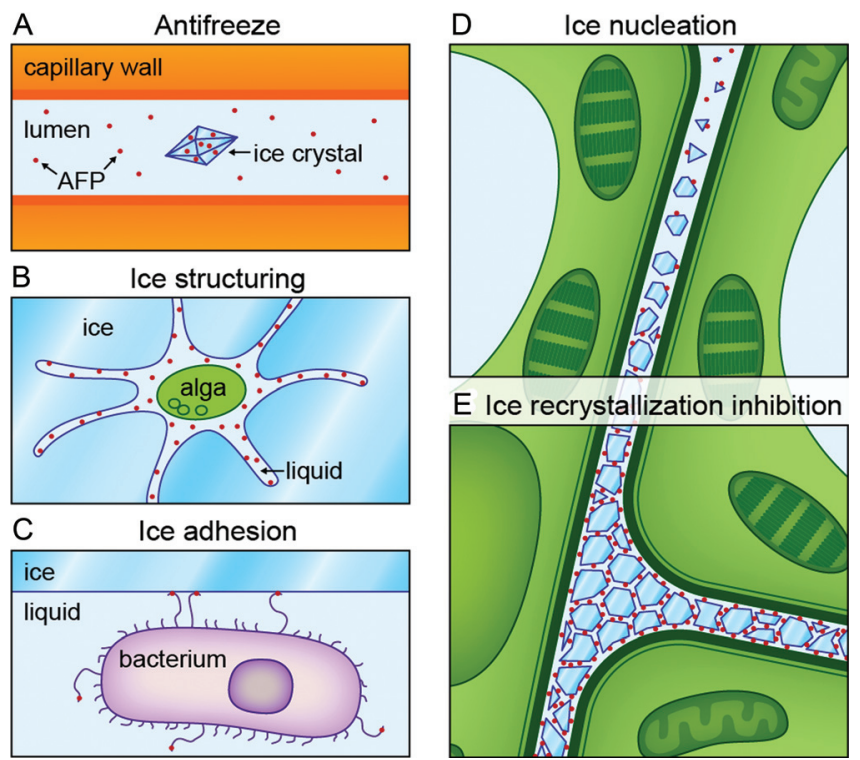

E Ice recrystallization inhibition

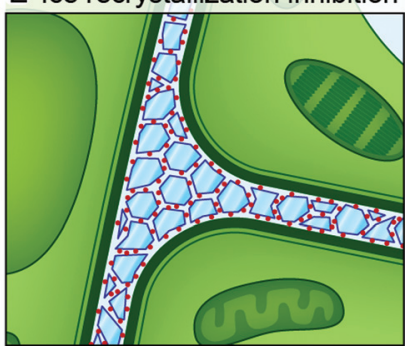

FIG. 1. Ice binding proteins display distinct biological functions. (a) $\mathrm{AF}(\mathrm{G}) \mathrm{Ps}$ in freeze-avoiding species such as fish lower the freezing point of serum, thereby blocking the growth of circulating, embryonic ice crystals. (b) IBPs produced by microorganisms like algae maintain a liquid environment within sea ice to live in. (c) The bacterium Marinomas primoryensis is covered with adhesins, containing an ice-binding domain to attach to ice on the surface of Antarctic lakes to gain access to oxygen and nutrient-rich waters. (d) Ice nucleation is initiated extracellularly by INPs in freezetolerant plants at relatively high subzero temperatures. (e) IBPs in freezetolerant species minimize freeze damage through inhibition of ice recrystallization such that extracellular ice grains remain small. Figure was adapted from Davies, Trends Biochem. Sci. 39, 548 (2014) (Ref. 41).

lysate. ${ }^{17-19}$ Inhibition of ice recrystallization is monitored by polarized optical microscopy. ${ }^{6,20}$ The IBPs can be separated from proteins and other (serum) constituents that do not bind ice by ice-affinity purification. ${ }^{21-23}$

Most important for freeze-avoiding species like fish is the ability of IBPs to prevent further growth of endogenous ice crystals circulating in the blood stream or hemolymph [Fig. 1(a)]. The "antifreeze activity" of this subclass of IBPs called antifreeze (glyco)proteins is quantified by the temperature range in which ice crystal growth is effectively blocked. AFPs create this so-called thermal hysteresis (TH) gap between the freezing and melting point of circulating ice crystals by a noncolligative freeze point depression. ${ }^{5,24}$ Insect AFPs tend to generate a larger thermal hysteresis gap than fish AFPs, since they live in much colder environments at temperatures as low as $-70^{\circ} \mathrm{C} .{ }^{13}$ Fish AFPs exhibit a maximum $\mathrm{TH}$ of $\sim 2{ }^{\circ} \mathrm{C}$ with serum levels as high as $30-40 \mathrm{mg}$ $\mathrm{ml}^{-1}$, while $2-13^{\circ} \mathrm{C} \mathrm{TH}$ values have been reported for the hemolymph of freeze-avoiding insects at tenfold lower AFP concentrations. ${ }^{13,25}$ At first sight, it seems as if fishes are well protected from freezing in sea water of $-1.9^{\circ} \mathrm{C}$, while insects remain at risk in their natural habitats. Insects, however, may be better protected than it seems on the basis of $\mathrm{TH}$ values determined in vitro, because the activity of insect AFPs increases with decreasing crystal size, which could be much smaller in nature than in a laboratory experiment. ${ }^{12,26}$
Moreover, freeze-avoiding insects use both AFPs and colligative substances, such as sugars and polyols, to prevent inoculative freezing (i.e., freezing initiated by external ice) and supercool down to very low temperatures. ${ }^{13,27}$ Potential ice nucleators are removed from the body or inactivated by IBPs. ${ }^{12,28-30}$

While ice-formation is lethal for freeze-avoiding organisms such as fish and most insects, freeze-tolerant plants and insects allow controlled freezing of extracellular spaces during the winter season. ${ }^{13,31}$ Because intracellular ice would also be lethal for freeze-tolerant species, they use INPs to prevent extensive supercooling and initiate extracellular ice nucleation at relatively low supercooling [Fig. 1(d)]. ${ }^{12,13}$ The osmotic imbalance that arises as a result of extracellular ice formation gives an outflux of water from the cells, which further depresses the intracellular nucleation and freezing points. ${ }^{12,13,31,32}$ Potent ice nucleating proteins are furthermore found on the membranes of bacteria, which gain access to food by freezing which injures the host plants or fruits. $12,33,34$

Apart from INPs, freeze-tolerant species also produce IBPs to control intercellular ice. Insect AFPs from freezetolerant species exhibit much lower TH values than their counterparts from freeze-avoiding species. ${ }^{25} \mathrm{~A}$ combination of low daylight exposure and low temperature triggers the production of AFPs in cold-adapted overwintering plants with typical TH values of $0.1-0.5^{\circ} \mathrm{C} .{ }^{31,35}$ Plant IBPs are also very effective inhibitors of ice recrystallization [Fig. 1(e)]. This circumvents the formation of large ice crystals in the interstitial fluids which causes freeze damage. ${ }^{8,36-38}$

Two additional biological functions of IBPs have come to light more recently. IBPs secreted from sea ice-inhabiting diatoms, fungi, and bacteria most likely have an icestructuring function. Together with other extracellular polysaccharide substances, a liquid environment is maintained in brine channels, which is essential for their habitability [Fig. 1(b)]..$^{6,739,40}$ The Antarctic bacterium Marinomas primoryensis also uses IBPs to alter its natural habitat, but instead of secreting IBPs to the environment, it adheres to ice floating on Antarctic lakes via 1.5-MDa ice-binding adhesins on its surface. This gives the bacterium access to oxygen and nutrition rich water [Fig. 1(c)]. ${ }^{10,11}$

\section{STRUCTURE OF ICE-BINDING PROTEINS}

All IBPs bind ice, yet, this unique class of proteins displays great structural diversity. The large variation in macromolecular structures, which is found even in closely related organisms (i.e., certain types of polar fishes), points toward an independent and recent evolution due to climate changes. ${ }^{42,43}$

\section{A. Classification and structure of ice-binding proteins}

IBPs are grouped into AFPs and other IBPs. AFPs are classified into nonfish and fish AFPs, which are further subdivided into five types based on their amino acid sequence and structural characteristics: AFGPs, and types I, II, III, and 
IV AFPs. Cold-adapted organisms typically produce AFPs from different structural classes and/or multiple isoforms of AFPs of the same type. ${ }^{31,42,44}$

AFGPs consist of $n=4-50$ tripeptide repeats of (Ala-AlaThr $)_{n}$ with the disaccharide galactose- $N$-acetylgalactosamine attached to each hydroxyl oxygen atom of the Thr residues. ${ }^{45,46}$ AFGPs are categorized into eight classes of isoforms with AFGP1 corresponding to the largest glycoproteins $\left(M_{\mathrm{w}}=34 \mathrm{kDa}\right)$ and AFGP8 to the smallest $\left(M_{\mathrm{w}}=2.6 \mathrm{kDa}\right){ }^{4}$ No solution structure is available for AFGPs, since they are polydisperse, flexible, and rather disordered. ${ }^{46}$ Fish type I AFPs also have a highly repetitive amino acid sequence. The two type I AFPs from winter flounder, for example, are rich in alanine and have an $\alpha$-helical fold with 11 -residue periodicity [Figs. 2(i) and 2(ii)]. ${ }^{47,48}$ In contrast, type II and III fish AFPs are nonrepetitive and show an overall globular fold. ${ }^{49,50}$ In fish type II AFPs, this fold is stabilized by cysteine residues. Herring $h$ AFP-II has five intramolecular cysteine bridges and binds one $\mathrm{Ca}^{2+}$ ion [Fig. 2(iii)]. ${ }^{51}$ Interestingly, the TH activity of the protein is significantly lower in the presence of other divalent ions, which also leads to different ice crystal shapes. ${ }^{52}$ Globular type III fish AFPs are devoid of cysteine. They are subdivided in quaternary aminoethyl (QAE) and sulfopropyl (SP) isoforms, based on sequence similarity and isoelectric point: QAE isoforms adhere to QAE sephadex ion exchange resin, while SP isoforms adhere to SP sephadex ion exchange resins. The frequently studied type III AFP from ocean pout belongs to the QAE isoforms [Fig. 2(iv)]. ${ }^{53,54}$ Only one fish type IV AFP has been discovered and characterized. It is present, however, in the blood of the longhorn sculpin at such low concentrations that it cannot function as an antifreeze agent. ${ }^{55}$
A common structural motif in IBPs from microorganisms and arthropods is the $\beta$-solenoid fold [Figs. 2(v)-2(ix)]. In MpAFP, $s b w$ AFP, TmAFP and $L p$ IBP the $\beta$-turns are formed by regular repeats [Figs. 2(vi), 2(vii), 2(viii), and 2(ix)]. ${ }^{56-58}$ On the contrary, in TisAFP [Fig. 2(v)], ColAFP from the bacterium Colwellia strain SLW05 (PDB 3WP9) and LeIBP from the yeast Leucosporidium (PDB 3UYU and 3UYV), $\beta$ loops are of different lengths and arranged in an irregular order. An $\alpha$-helix lies alongside the $\beta$-helix axis. ${ }^{59-61}$ Yet other IBP structures are found in insect RiAFP and sfAFP. The structure of RiAFP of the beetle Rhagium inquisitor is formed by two closely packed $\beta$-sheets [Fig. 2(x)]. ${ }^{62}$ Six antiparallel polyproline type II (PPII) left-handed helices are observed in the structure of $s f \mathrm{AFP}$ from snow flee [Fig. 2(xi)]. ${ }^{63}$

The global protein structure of some IBPs is stabilized by $\mathrm{Ca}^{2+}$ ions. A row of aligned $\mathrm{Ca}^{2+}$ ions can be observed in MpAFP from the bacterium Marinomas primoryensis [Fig. $3(\mathrm{a})],{ }^{56}$ and a single $\mathrm{Ca}^{2+}$ ion is bound in type II $h$ AFP from herring. 51,64

\section{B. Structure of the ice-binding site}

The relatively flat and hydrophobic region that contacts ice upon binding is termed the "ice binding site" (IBS) of the IBP. Amino acid residues of the IBS have frequently been identified via mutagenesis studies. ${ }^{50,66,67}$ Mutations of amino acids that are important for ice binding result in a large reduction of thermal hysteresis activity. For example, the Thr and Ala residues that are important for ice binding of $w f$ AFP-I are all located on one relatively flat and hydrophobic side of the $\alpha$-helix. ${ }^{68}$ The role of the threonine residues
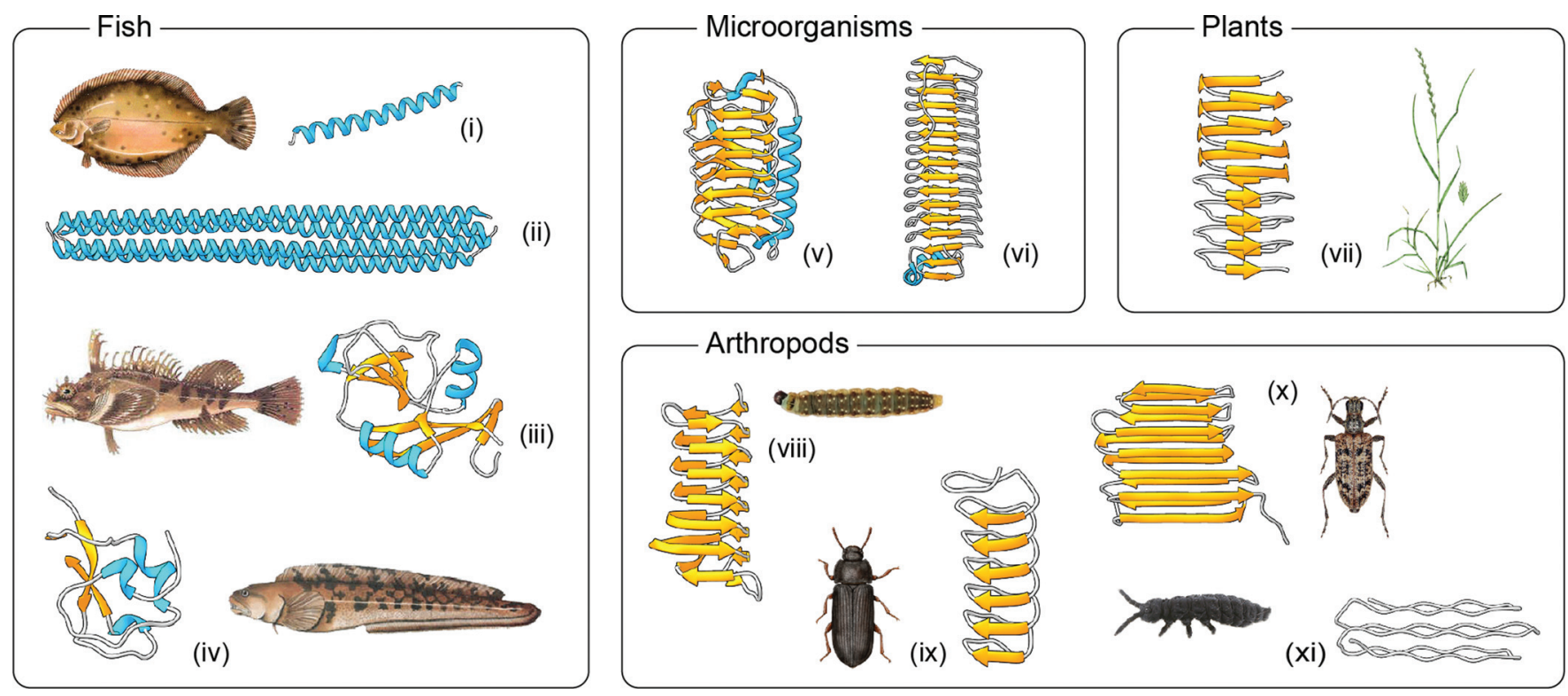

FIG. 2. Overview of structures of antifreeze proteins from various kingdoms of Life. (i) Type I wfAFP from winter flounder (PDB: 1WFA) (Ref. 47), (ii) type I hypAFP1, also known as Maxi, from winter flounder (PDB: 4KE2), (iii) type II $h$ AFP from herring (PDB: 2PY2) (Ref. 51), (iv) type III opAFP (HPLC12) from ocean pout (1HG7) (Ref. 53), (v) TisAFP6 from gray snow mold fungus (PDB: 3VN3) (Ref. 60), (vi) MpAFP from an Antarctic bacterium (PDB: 3P4G) (Ref. 56), (vii) LpAFP from winter ryegrass (PDB: 3ULT) (Ref. 65), (viii) sbwAFP from spruce budworm (PDB: 1M8N) (Ref. 57), (ix) TmAFP from mealworm beetle (PDB: 1EZG) (Ref. 58), (x) RiAFP from ribbed pine borer (PDB: 4DT5) (Ref. 62), and (xi) sfAFP from snow flea (PDB: 2PNE) (Ref. 63). Secondary structural elements are indicated as follows: $\alpha$-helix (cyan), $\beta$-sheet (orange), and coil (gray). 

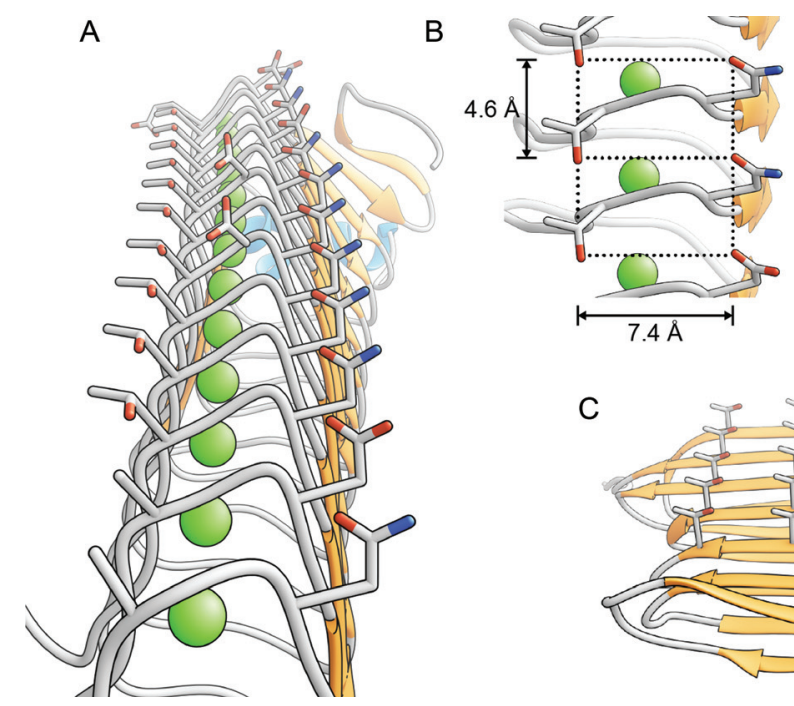

D

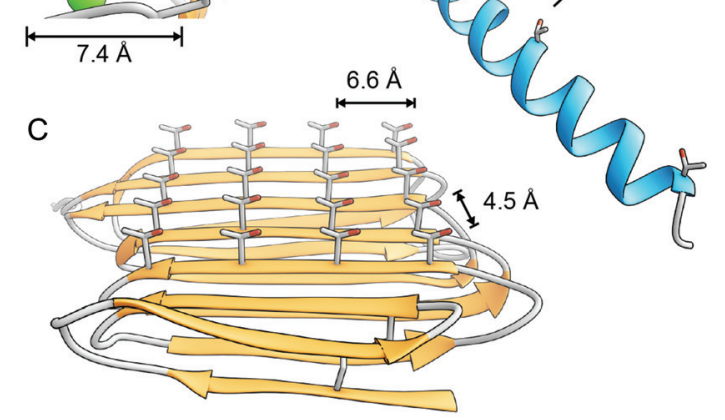

FIG. 3. Ice-binding sites with regularly ordered threonine residues. (a) The oxygen atoms of the Thr and Asn/Asp residues in the IBS of MpAFP from Marinomas primoryensis are regularly ordered (b) with $7.4 \times 4.6 \AA$ spacing (Ref. 56). (c) Four rows of threonine residues are located in the IBS of RiAFP with $6.66 \times 4.73 \AA$ spacing (Ref. 62). (d) A single row of threonine residues is formed on the IBS of type I AFP from winter flounder with $16.5 \AA$ interresidue spacing (Ref. 47).

was examined in detail via site-directed mutagenesis to either serine (loss of $\gamma$-methyl group) or valine (loss of $\mathrm{OH}$ group). Replacing Thr by Ser caused a reduction in antifreeze activity, while a Thr to Val mutation had little effect. This suggests that the $\gamma$-methyl group rather than hydrogen bonding of the $\mathrm{OH}$ group of threonine is important for binding to ice. ${ }^{69}$

While for most IBPs the IBS is localized on one face of the protein that can bind to either one or several ice crystal plane(s), in some cases, a "compound" IBS is identified. ${ }^{59,67}$ Type III AFP from notched fin eel pout and ocean pout have an IBS composed of two regions positioned at an angle of roughly $150^{\circ}$ with respect to each other. One binds the primary prism plane of ice; the other a pyramidal plane [Fig. $8(\mathrm{a})] .{ }^{67}$ Additionally, two ice binding faces with an angle of $141^{\circ}$ were recently identified in an sheet and loop region of ColAFP. A double mutant inhibiting ice binding in both regions greatly reduced antifreeze activity. Both ice binding sites could be docked onto several ice crystal planes, including the basal plane. ${ }^{59}$

The IBS of several AFPs contains residues arranged with remarkably high order (Fig. 3). For example, TmAFP and $s b w$ AFP display two arrays of Thr-residues. ${ }^{58,70}$ Similarly, a row of Thr residues and a row of Asx (mostly Asn) residues appear in the IBS of MpAFP [Figs. 3(a) and 3(b)] ${ }^{56}$ The Thr-side chains have the same rotameric position and the spacing between side chains $(7.4 \times 4.6 \AA)$ matches the ice lattice on the basal plane $(7.83 \times 4.52 \AA)$ as well as on the prism plane $(7.35 \times 4.52 \AA)$. Furthermore, the crystal structure of RiAFP from the beetle Rhagium inquisitor showed four instead of two arrays of threonine residues with a $6.66 \times 4.73 \AA$ spacing [Fig. 3(c)].$^{62}$ A single row of ordered Thr-residues with a spacing of $16.5 \AA$ is observed in wfAFPI [Fig. 3(d)], which matches with the $16.7 \AA$ repeat in the $\{2$ $0 \overline{2} 1$ \} pyramidal plane. ${ }^{47,68}$ On the contrary, examples of ice binding sites without apparent structure are also known, even in IBPs with $\beta$-solenoid structure, such as TisAFP, L $p \mathrm{IBP}$, LeIBP, and ColAFP. Despite this lack regularity in the IBS these proteins are able to bind both basal and prism planes. ${ }^{59-61,65}$

Crystal structures of various AFPs reveal ordered waters associated with the protein IBS, ${ }^{48,56,58,65}$ which are thought to play an important role in ice-binding (see Sec. VIE for more details).

\section{ACTIVITY ASSAYS OF ICE BINDING PROTEINS}

The activity of IBPs is routinely measured on a macroscopic level in an activity assay that quantifies the impact of IBPs on ice crystal growth. For example, the extent of freezing-point depression due to AFPs is determined in a thermal hysteresis activity assay. Furthermore, one can specifically probe the interaction between IBPs and ice in a (fluorescence) ice-binding plane affinity assay. This method relies on the oriented growth of a single-crystal ice hemisphere to reveal onto which ice crystal plane(s) IBPs bind.

\section{A. Thermal hysteresis activity}

Common antifreezes like salts and alcohols lower the freezing point in a colligative fashion. The freezing point depression depends linearly on the solution osmolality and can be calculated according to $\Delta T_{F}=K_{F} \times b \times i$, where $\Delta T_{F}$ is the freezing point depression, $K_{F}$ is the cryoscopic constant which depends on the solvent, $b$ is the molality, and $i$ is the van't Hoff factor. For example, a $1 \mathrm{mM} \mathrm{NaCl}$ solution in water gives a freezing point depression $\Delta T_{F}$ $\sim-0.004{ }^{\circ} \mathrm{C}$. In contrast, $\mathrm{AF}(\mathrm{G}) \mathrm{Ps}$ lower the freezing point in a noncolligative fashion. For instance, a $1 \mathrm{mM} w f$ AFP-I solution gives $\sim 0.53^{\circ} \mathrm{C}$ freezing point depression (Fig. 4). ${ }^{71}$ Clearly, $\mathrm{AF}(\mathrm{G}) \mathrm{Ps}$ are far more effectively antifreezes on a 
molar basis. Unlike colligative antifreezes, $\mathrm{AF}(\mathrm{G}) \mathrm{Ps}$ depress the freezing point relative to the melting point, which creates a so-called thermal hysteresis gap. ${ }^{24}$ The magnitude of this gap is a quantitative measure of the Thermal hysteresis activity or antifreeze activity, since further growth of embryonic ice crystals is blocked in this temperature range. The magnitude of this TH gap is taken as a quantitative measure of AFP activity. It can be influenced by various means, e.g., ions,, 72 other low molecular weight solutes, ${ }^{73}$ and proteins that interact with AFPs. ${ }^{74}$

In a classical thermal hysteresis assay, a nanoliter freezing point osmometer setup is used to grow a small ice crystal with a single crystallographic orientation within a $\sim 10 \mathrm{nl}$ IBP sample droplet immersed in an oil droplet. Flashfreezing initiates the formation of ice crystals, which are subsequently melted until a single, small crystal of $\sim 10 \mu \mathrm{m}$ remains. Hereafter, the sample temperature is slowly lowered until a sudden growth "burst" occurs [Fig. 4(a)]. This temperature is recorded as the nonequilibrium freezing temperature. In such a cryoscopy assay, the freezing and melting temperatures, $T_{\mathrm{f}}$ and $T_{\mathrm{m}}$, respectively, are thus determined by analysis of a series of video frames taken upon slow cooling and heating of the IBP sample. ${ }^{75}$ This gives the $\mathrm{TH}=\left|T_{\mathrm{f}}\right|-\left|T_{\mathrm{m}}\right|$ activity of AFPs, which increases linearly with the square root of the molar AFP concentration [Fig. 4(b)]. ${ }^{71}$

Assaying thermal hysteresis by cryoscopy has two major advantages: minute sample volumes of $\sim 10 \mathrm{nl}$ are required and IBP-induced ice shaping (vide infra) can be observed simultaneously. Disadvantageously, the technique is laborintensive, and results may be poorly reproducible, especially for insect AFPs, which exhibit TH activity that is strongly dependent on the experimental conditions, such as the ice crystal size, the cooling rate, and the annealing time during which the ice crystal is exposed to the AFPs. ${ }^{76,77}$ This is exemplified in a comparison of $\mathrm{TH}$ values measured by cryoscopy and alternative methods, such as the capillary technique wherein relatively large crystals of $\sim 0.25 \mathrm{~mm}$ in size are studied. The capillary technique yields lower $\mathrm{TH}$ values than cryoscopy, since the TH activity of insect AFPs increases with decreasing ice crystal size. An aqueous solution of AFPs purified from the beetle $D$. canadensis gives $\mathrm{TH}=1.4^{\circ} \mathrm{C}$ in the capillary technique and $\mathrm{TH}=5.5^{\circ} \mathrm{C}$ in cryoscopy. ${ }^{13}$

A robust and automated method for $\mathrm{TH}$ determination based on sonocrystallization was recently developed by Gaede-Koehler et al. to enable high-throughput analysis of novel antifreezes. ${ }^{78}$ In this assay, $\sim 1 \mathrm{ml}$ of an AFP solution is supercooled in a well-defined cooling ramp, after which ice nucleation is initiated by a short ultrasound pulse (Fig. 5). This results in an increase in the temperature of the sample, due to released latent heat of crystallization, which stabilizes at the nonequilibrium freezing point. Several minutes after the pulse, slow melting of the sample is initiated by a welldefined heating ramp. This scheme enables an independent and automated measurement of the freezing and melting point of samples within a single experiment using a Pt-100 resistance thermometer.

\section{B. IRI activity}

Ice recrystallization is a thermodynamically driven, spontaneous process where large ice crystal grains grow at the expense of smaller ones. This results in a decrease in the grain boundary area per unit volume of ice, thereby lowering the free energy of the system. We distinguish between three types of recrystallization: isomass, accretive, and migratory recrystallization [Fig. 6(a)]. ${ }^{9,79}$ The latter is often ascribed as the primary ice recrystallization process. Isomass recrystallization occurs through changes in the shape or internal structure of ice crystals. Irregular grain surfaces are rounded-off, and ice crystal defects are reduced. Accretive
A

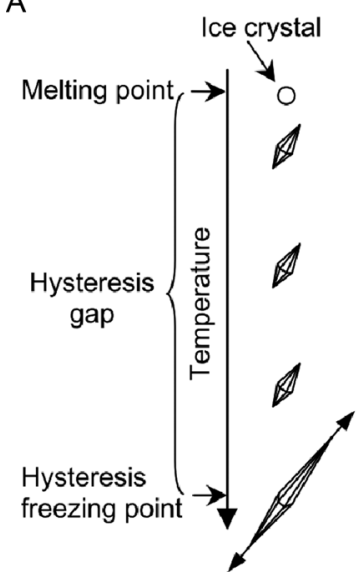

B

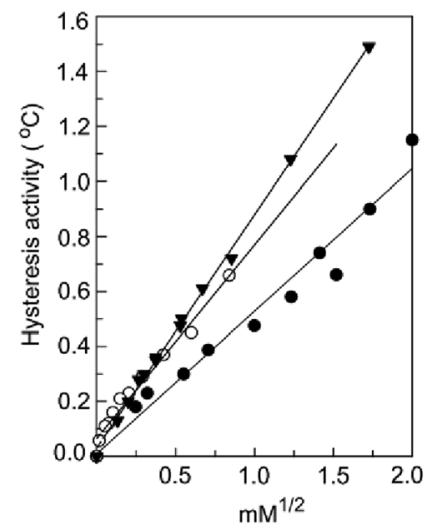

C

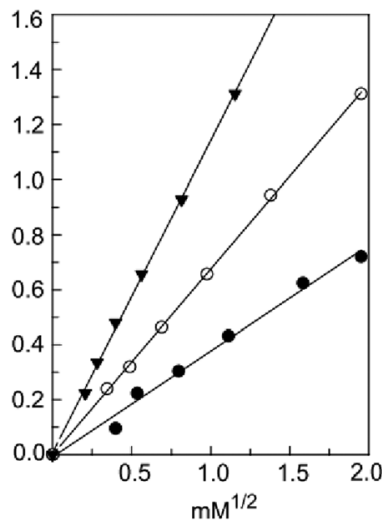

FIG. 4. Thermal hysteresis activity by cryoscopy. TH is the depression of the freezing point of a solution relative to its melting point. (a) In a cryoscopy assay of TH, a single ice crystal is created in an AFP solution. The temperature of the solution is lowered, upon which the ice crystal adopts a characteristic morphology, which reflects the ice crystal plane affinity of the AFP. When the sample temperature reaches a value below the hysteresis freezing point, a sudden growth burst of the ice crystal occurs. (b) The TH activity of AFPs depends linearly on the square root of their concentration. Symbols correspond to TH values measured by cryoscopy for type I AFP from winter flounder $(\bullet)$, recombinant $(\bigcirc)$, and synthetic $(\boldsymbol{\nabla})$ type II from sea raven, $(c)$ antifreeze glycoproteins of 7900 $\mathrm{Da}(\bullet), 10.500 \mathrm{Da}(\bigcirc)$, and 28.800 Da $(\boldsymbol{\nabla})$. Figures were adapted from Kristiansen and Zachariassen, Cryobiology 51, 262 (2005). 


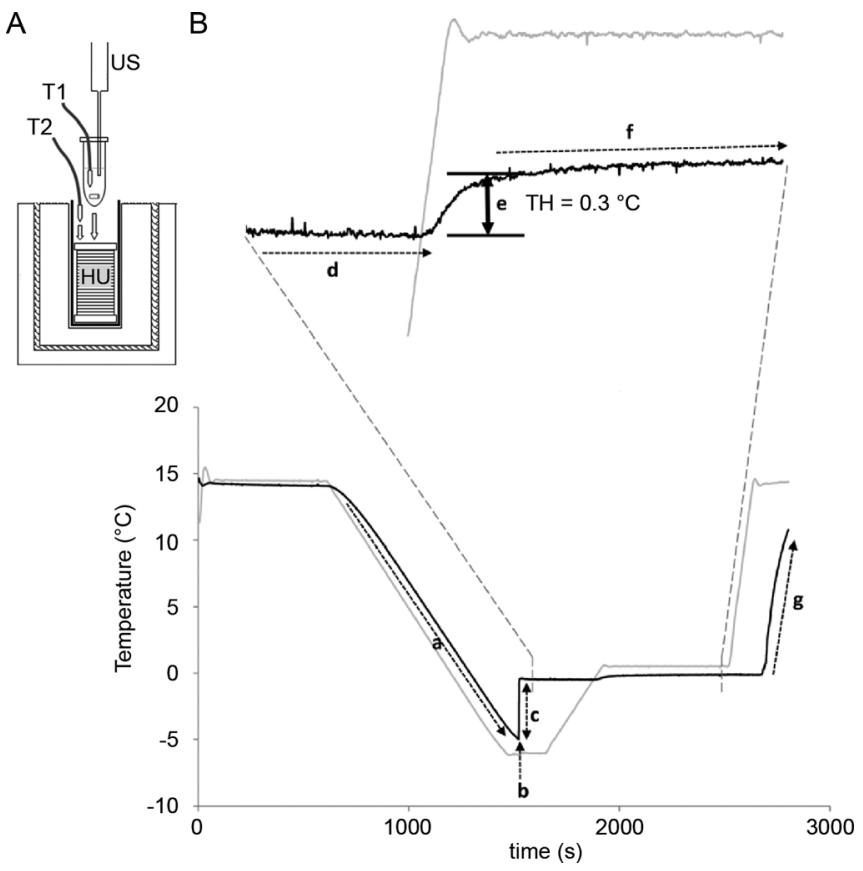

FIG. 5. Thermal hysteresis activity by sonocrystallization. A robust and reliable TH assay for high-throughput analysis of antifreezes based on sonocrystallization works as follows. (A) First, a small sample vial with a $\sim 1 \mathrm{ml}$ IBP solution, a Pt-100 resistance thermometer T1, and an ultrasonic sonotrode US are placed in a heat unit HU kept at a set temperature controlled by a second Pt-100 sensor T2. (B) Next, the IBP solution is (a) supercooled until $-5{ }^{\circ} \mathrm{C}$ after which (b) a sonocrystallization puls causes (c) a rapid temperature increase due to ice formation until (d) the sample temperature stabilizes at the freezing plateau. (e) The thermal hysteresis is derived from the difference between the (d) freezing plateau and (f) melting plateau. The gray and black solid lines indicate the HU temperature set by $\mathrm{T} 2$ and the sample temperature recorded by $\mathrm{T} 1$, respectively. Figure adapted from Gaede-Koehler et al., Anal. Chem. 84, 10229 (2012).
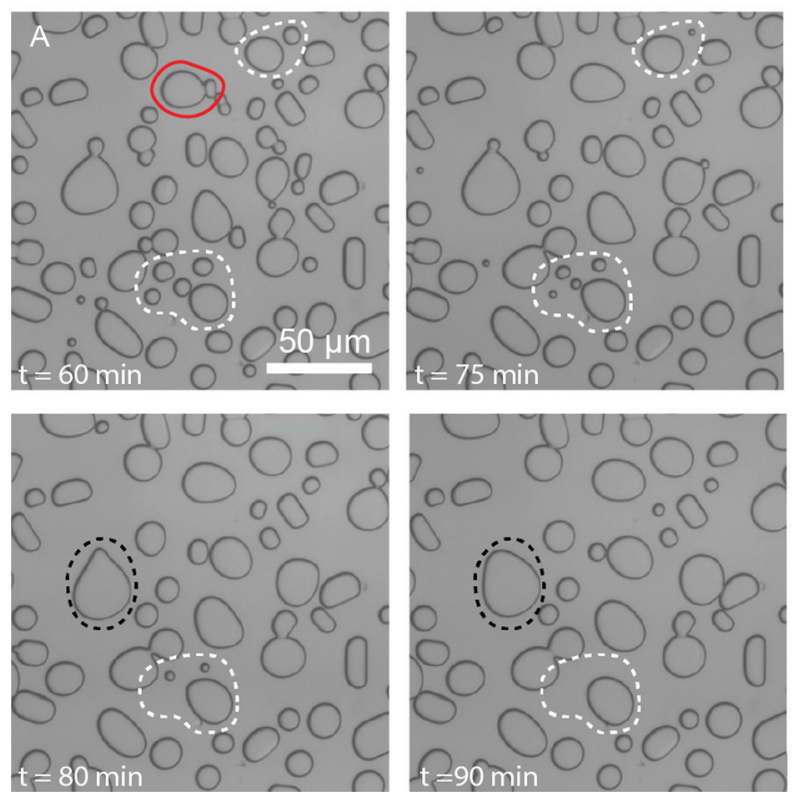
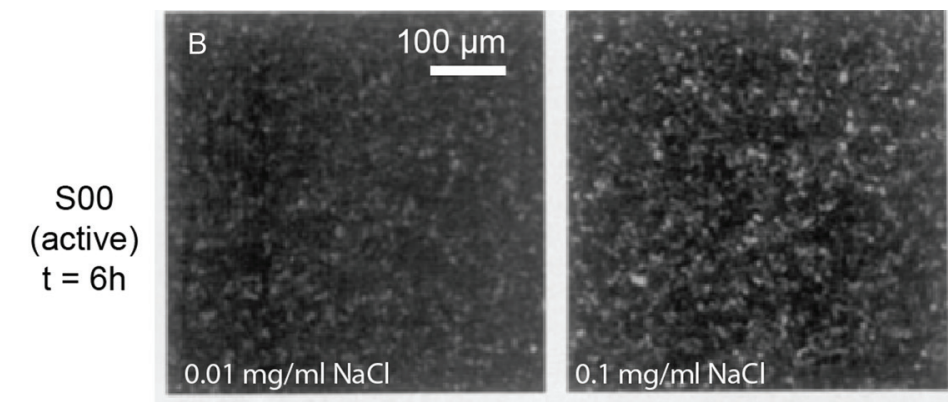

recrystallization refers to the fusion of two or more neighboring crystals. Migratory crystallization, also known as Ostwald ripening, occurs when large crystals grow while small ones (with small radii and relatively large surface energy) disappear at constant ice volume fraction, temperature, and pressure. ${ }^{9,79}$ IBPs already inhibit recrystallization at very low, micromolar concentrations. ${ }^{9}$ This inspired the design of biomimetic antifreezes for use in biomedical applications such as red blood cell preservation. ${ }^{80,81}$

In an ice recrystallization inhibition (IRI) activity assay, a thin wafer of fine polycrystalline ice is annealed at a subzero temperature (typically $-6^{\circ} \mathrm{C}$ ) for several hours during which the time-evolution of the size of individual ice grains is analyzed by optical microscopy. The lowest IBP-concentration where ice recrystallization cannot be observed, the IRIendpoint, is often reported to describe the IRI activity of the IBP. ${ }^{8,82}$ IRI assays are best performed in the presence of low molecular weight solutes like sucrose or $\mathrm{NaCl}$. These accelerate recrystallization and ensure a sufficiently large liquid fraction (which coexists with the ice crystals in the sample) to discriminate between IRI-active compounds that bind ice and IRI-inactive compounds that do not bind ice [Fig. 6(b)].

Several methods have been developed to obtain thin wafers of fine-grained polycrystalline ice required for IRI assays. All rely on rapid cooling of the sample under investigation. Knight et al. developed the "splat cooling" method wherein a $10 \mu$ droplet of an IBP solution falls $3 \mathrm{~m}$ in height through a $12 \mathrm{~cm}$ plastic tube onto an aluminum plate kept in dry ice at a temperature of $-78^{\circ} \mathrm{C}^{83}$ Smallwood et al. developed an alternative sample preparation method. Herein, an IBP solution is sandwiched between two coverslips and subsequently dropped into a bath of heptane held at $-80^{\circ} \mathrm{C}$

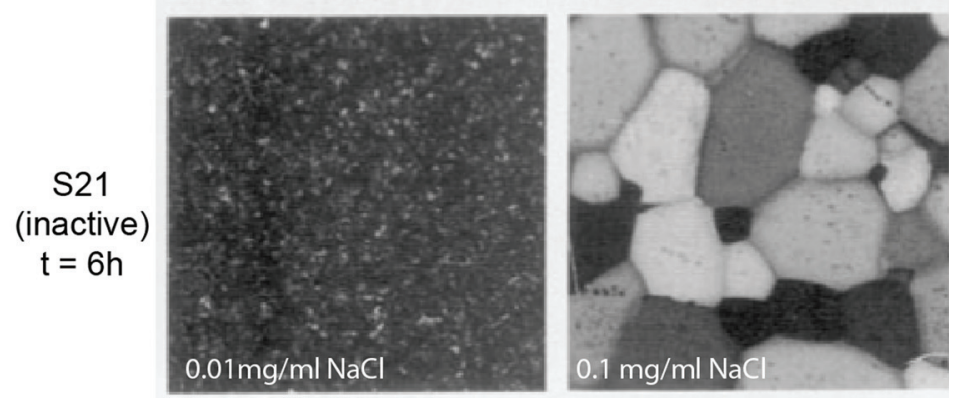

FIG. 6. Sandwich and splat-assay to probe inhibition of ice recrystallization. (a) Sandwich assay of ice recrystallization in a solution of $30 \%$ sucrose in water at $-7^{\circ} \mathrm{C}$ showing accretive (red solid delineation), isomass (black dashed delineation) and migratory (white dashed delineation) recrystallization (unpublished results). (b) Splat-assay of IRI activity of antifreeze peptide analogs. At low solute concentrations both inactive (S21) and active (S00) compounds showed IRI at $0.02 \mathrm{mg} / \mathrm{ml}$ after $6 \mathrm{~h}$ annealing at $-6^{\circ} \mathrm{C}$, while only S00 showed IRI in the presence of $\geq 0.1 \mathrm{mg} / \mathrm{ml} \mathrm{NaCl}$. Figure adapted from Knight et al., Biophys. J. 59, 409 (1991). 
by solid $\mathrm{CO}_{2} \cdot{ }^{36}$ Both methods yield fine-grained ice, because rapid heat removal and large undercooling yield a large number of ice nuclei. ${ }^{9,84}$

To quantitatively compare the IRI activity of ice-binding compounds, automated image analysis routines have been developed to monitor the time-evolution of the mean ice grain size, $r$, and mean largest grain size ${ }^{80,86,87}$ The Koop laboratory demonstrated that $r^{3}$ increases linearly with time in 45 wt. \% sucrose solutions as predicted by Lifshitz-SlyosovWagner (LSW) theory [Fig. 7(a)]. ${ }^{79,88,89}$ This is in accord with Ostwald ripening being the primary cause of ice recrystallization under these conditions. The addition of (synthetic mimics of $\mathrm{AF}(\mathrm{G}) \mathrm{Ps}$ considerably reduced the growth rate constant $k$ in a concentration-dependent manner. The midpoint $c_{\mathrm{i}}$ of the sigmoidal decrease in $k$ with the increasing IBP concentration is taken as a quantitative measure of IRI [Fig. 7(b)], enabling an activity ranking of biological and synthetic antifreezes. ${ }^{80,89}$ Below the inhibitory concentration $c_{\mathrm{i}}$, the rate of ice grain growth is limited by water diffusion, while the decelerated rate of liquid-to-ice-transfer is rate limiting at higher AFGP concentrations.

\section{Dynamic ice shaping}

Once an embryonic ice crystal adopts its specific, IBPinduced morphology, further growth is completely arrested within the thermal hysteresis gap. The shape of these ice crystals reflects the affinity of IBPs for the various ice crystal planes. Virtually, all natural ice grows in an hexagonal lattice described by four crystallographic axes $\left(a_{1}, a_{2}, a_{3}\right.$, and $\left.c\right)$, as shown in Fig. 8(a). Fish AFPs bind on the prism and pyramidal planes of ice, thereby limiting ice growth in the $a_{1}, a_{2}$, and $a_{3}$ directions [Fig. 8(b)]. As a result, fish AFPs shape ice crystals into hexagonal bipyramids, thus minimizing the size of the basal planes (devoid of AFPs), which form a small tip [Fig. 8(b), i-iii, v]. In contrast, ice crystals grown in the presence of other IBPs that bind basal planes of ice adopt a flat hexagonal [Fig. 8(b), iv] or lemon-shaped form [Fig. 8(b), vi]. Upon slow cooling to temperatures below the thermal hysteresis gap, a growth burst of IBP-covered ice crystals is observed, which occurs along the $c$-axis for nonbasal plane binding IBPs and normal to the $c$-axis for basal plane binding IBPs. ${ }^{90}$ Monte Carlo simulations on ice crystal growth in the presence of fish and insects AFPs display these experimentally observed growth habits. ${ }^{91}$ Computational studies by Strom et al. explain the ice-shaping into characteristic morphologies by fish resp. insect IBPs with a one-dimensional resp. two-dimensional periodic bond chain matching mechanism leading to surface pinning. ${ }^{92,93}$

\section{Ice nucleation activity}

Ice nucleating proteins promote ice nucleation at small subzero temperatures. Generally, when a solution is supercooled below the melting point or (equilibrium) freezing point, it remains in the liquid state until the "supercooling point" or "nucleation temperature" is reached. At this temperature, ice-like aggregates of large enough size form nuclei and result in freezing. ${ }^{12}$ INPs increase the nucleation temperature, which induces freezing at elevated supercooled temperatures. This is because the ice-binding site of INPs provides a platform for the organization of water molecules in an icelike lattice which favors nucleation. Various droplet-freezing assays have been developed to study the impact of INPs and other compounds on the temperature of ice nucleation (Fig. 9). ${ }^{95,96}$ Since nucleation is a stochastic process that is highly susceptible to numerous factors that are difficult to control, ice nucleation activity assays have to be performed multiple times to ensure proper statistical sampling. ${ }^{97}$

\section{E. Ice plane affinity analysis}

Since adhesion to ice is the primary requirement for IBP activity, analytical tools have been developed to determine which ice crystal planes IBPs bind. Knight et al. developed an ice-etching technique, wherein a single ice crystal is grown from a dilute IBP solution to give a large ice hemisphere, which presents all interface orientations and which is furthermore positioned in a defined crystallographic orientation. ${ }^{85,99}$ The regions where IBPs accumulate appear upon
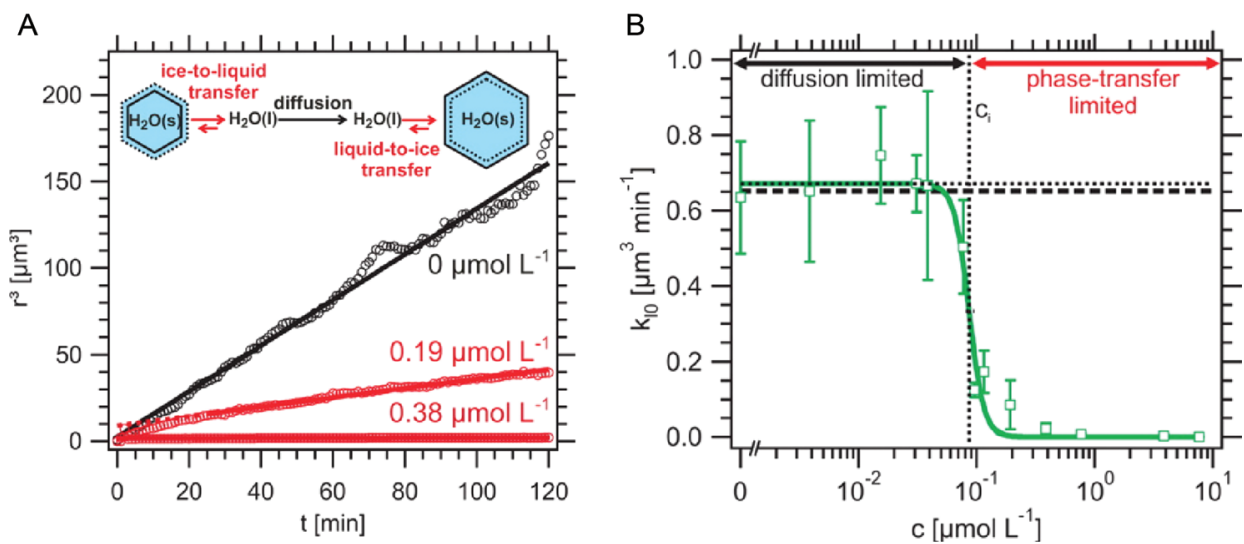

FIG. 7. Time evolution of ice grain growth in the presence of inhibitors of ice recrystallization. (a) In accord with the LSW theory, the mean ice grain volume $r^{3}$ increases linearly with time below a threshold concentration of AFGP8. (b) The inhibitory concentration, $c_{\mathrm{i}}$, can be used to rank ice-binding compounds in order of increasing IRI-activity. This is the midpoint of the sigmoidal decrease of the ice growth rate constant $k$ as a function of IBP concentration. Figures adapted from Budke et al., Cryst. Growth Des. 14, 4285 (2014). 
A
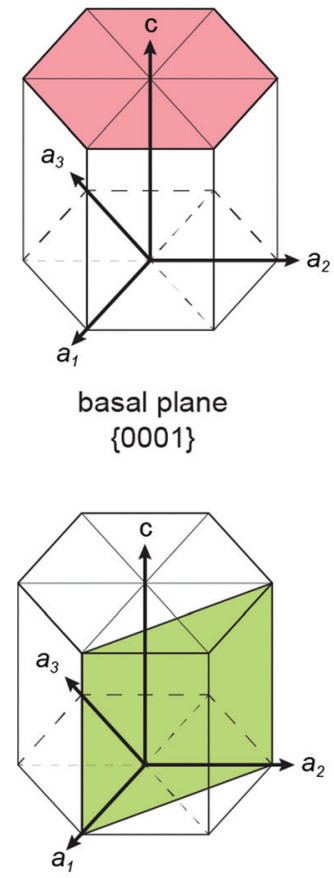

secondary prism plane $\{11 \overline{2} 0\}$
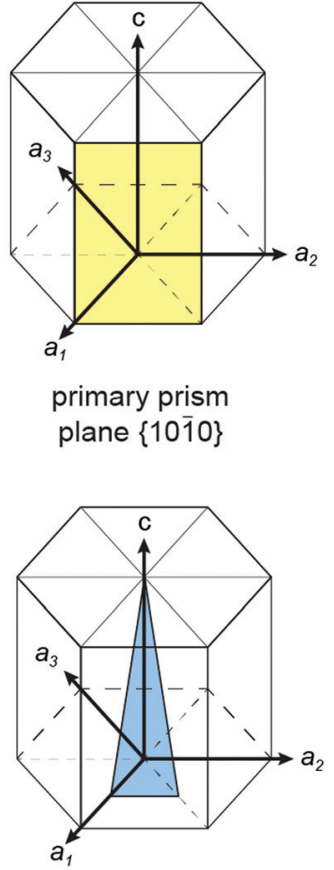

pyramidal plane $\{20 \overline{2} 1\}$
B

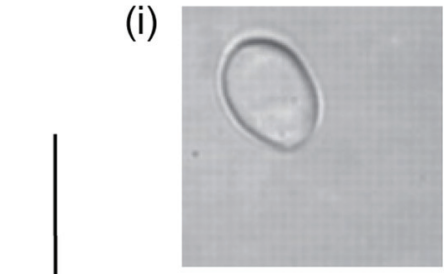

(i)

(ii)

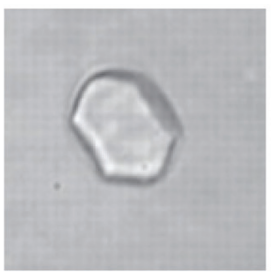

(iii)

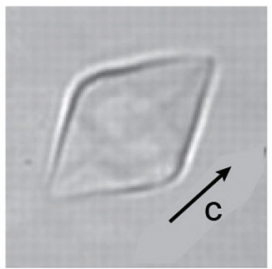

(iv)

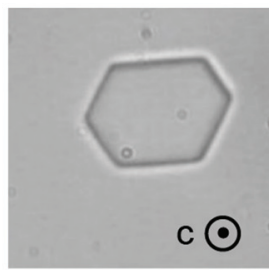

(v)

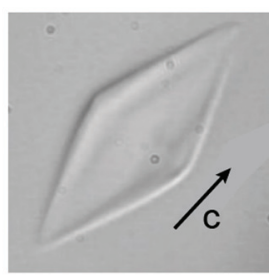

(vi)

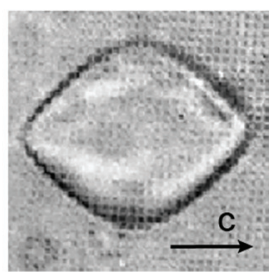

FIG. 8. Dynamic ice shaping of ice crystals by IBPs. (a) Ice grows under physiological conditions in an hexagonal lattice with axis ( $a_{1}, a_{2}, a_{3}$, and $c$ ). The unit cell shows a basal plane (pink), primary prism plane (yellow), a secondary prism plane (green), and a pyramidal plane (blue). IBPs shape ice crystals into distinct morphologies which reflect the affinity of IBPs for the various ice crystal planes. (b) An ice crystal grows into an hexagonal bipyramidal in 12 min in the presence of $500 \mu \mathrm{M}$ AGFP (primarily the $2650 \mathrm{Da}$ isoform) (i)-(iii). MpAFP, wfAFP-I and TmAFP shape ice into flat hexagonal plates (iv), hexagonal bipyramids (v), and lemon-shaped crystals (vi). Arrows indicate the c-axis direction. Figures adapted from Bar-Dolev et al., J. R. Soc. Interface 9, 3249 (2012) (Ref. 94), Garnham et al., Proc. Natl. Acad. Sci. 108, 7363 (2011), and Graham et al., Nature 388, 727 (1997).

slow sublimation of the outer part of the hemisphere enabling determination of the ice-binding plane [Fig. 10(a)]. Recently, this method was adapted to facilitate IBP detection on their affinity plane by fluorescence, which circumvents the need for sublimation [Figs. 10(b) and 10(c)]. ${ }^{100}$ Prior to such a fluorescence based ice-plane affinity (FIPA) assay, IBPs are either coupled to a fluorescent dye or to a fluorescent protein in a fusion protein construct.

\section{INTERACTION OF ICE BINDING PROTEINS WITH ICE}

The activity of IBPs is the result of their unique ability to interact with ice crystals. Insight into the nature of this interaction helps to understand how IBPs function and is furthermore essential for the knowledge-based design of potent biomimetic antifreezes.

\section{A. Adsorption-inhibition model}

In a seminal paper, Raymond and DeVries described a step-pinning model to explain how IBPs block ice crystal growth. ${ }^{101}$ If AFPs adsorb irreversibly in the path of a growth step on embryonic ice crystals, the proteins act as an impurity enforcing ice to advance between the adsorption sites. Above a threshold surface coverage, this raises the curvature of the growing ice front, which depresses the freezing point via the Gibbs-Thomson or Kelvin effect [Fig. 11(a)]. Steps no longer move and further ice growth is arrested within the thermal hysteresis gap. It is important to point out that while impurities alter crystal growth through step-pinning, incorporation, kink blocking, and lowering of the interfacial energy, only step-pinning can block crystal growth altogether. ${ }^{101,102}$ A step-pinning mechanism also naturally bears out the square-route dependence of activity on IBP concentration, ${ }^{101,102}$ which is observed in numerous experimental studies. ${ }^{71}$ Monte Carlo simulations on entire 3D ice crystals in the presence of TmAFP and wfAFP-I are also in line with this theory of antifreeze activity since ordered step growth appears inhibited. $^{91}$

The prevailing adsorption-inhibition model has been extended and revisited by various groups to account for nonstepwise growth on rough prism planes ${ }^{86,103,104}$ and dynamic exchange between adsorbed and free AFPs in a two-step mechanism. ${ }^{105}$ Knight et al. pointed out that IBPs block normal growth preventing layer growth instead of lateral growth impeding step passage (Fig. 11), since all ice crystal planes except the basal plane are molecularly rough. ${ }^{86,103,104}$ An insightful study by Kristiansen and Zachariassen builds upon the original adsorption-inhibition model, but argues that it is a pressure build-up due to convex ice growth that underlies the Gibbs-Thomson effect. ${ }^{71}$ Alternative models consider 


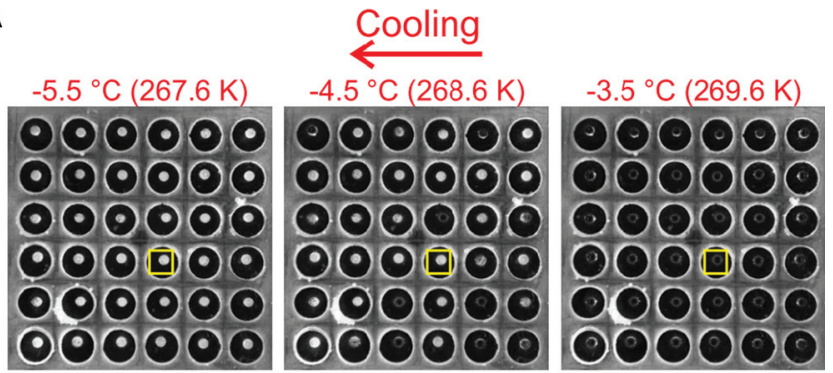

B

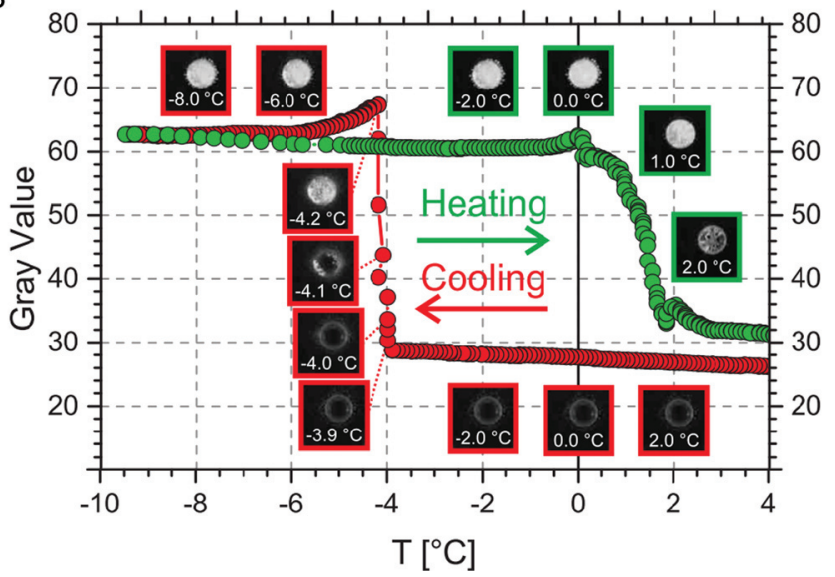

FIG. 9. Droplet assay of ice nucleation activity. (a) Nucleation events are automatically detected in droplets (each containing $0.1 \mu \mathrm{g}$ Snowmax ${ }^{\circledR}$ ) by a change in brightness upon cooling. (b) The onset of freezing and melting of individual droplets is determined from the temperature-dependence of the measured gray value. The droplets indicated by the yellow box in panel (a) freezes at $-3.9{ }^{\circ} \mathrm{C}$ and melts at $0.0^{\circ} \mathrm{C}$. Figure adapted from Budke and Koop, Atmos. Meas. Tech. 8, 689 (2015) (Ref. 98).

the anisotropic surface energy of ice, ${ }^{106}$ reversible adsorption, ${ }^{107-111}$ the polymeric nature of IBPs, ${ }^{112,113}$ and lowering of the interfacial tension or step energy. ${ }^{114,115}$

\section{B. Reversible or irreversible ice-binding?}

Various advanced experimental methods have been utilized to test the validity of (the assumptions underlying) the current models of antifreeze activity. These studies
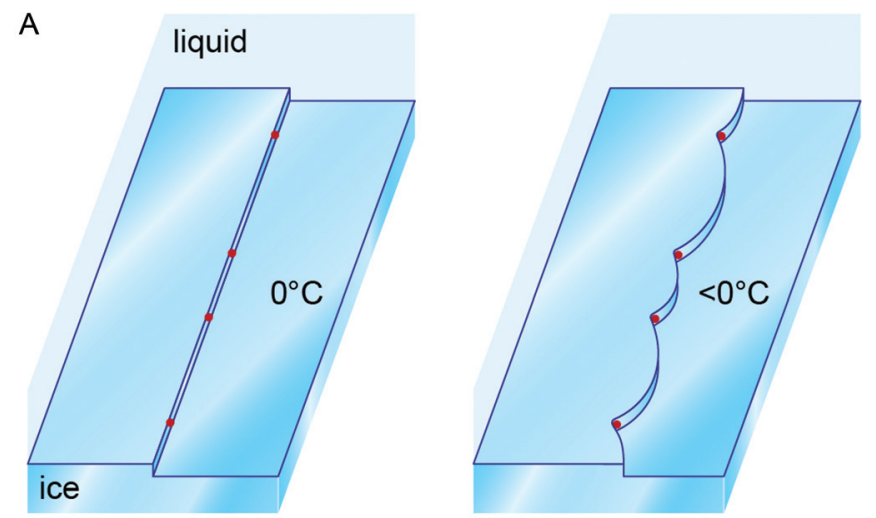

B

liquid

$0^{\circ} \mathrm{C}$

ice

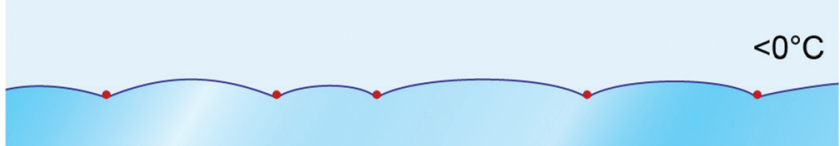

FIG. 11. Adsorption-inhibition model of antifreeze activity. Schematic representation of the (a) original and (b) adapted adsorption-inhibition model. Irreversibly adsorbed IBPs (depicted as red dots) raise the curvature of the growing ice front, which lowers the freezing point and inhibits further ice growth (a) in the lateral direction by step-pinning or (b) in the normal direction by surface-pinning (b). Figure adapted from Knight et al., Biophys. J. 59, 409 (1991).

focused on, e.g., the nature of the IBP/ice interaction, ${ }^{116-119}$ melting hysteresis, ${ }^{24,120}$ the IBP accumulation rate, ${ }^{121}$ the concentration-dependence of TH activity, ${ }^{122}$ the origin and the consequences of ice-binding plane specificity, ${ }^{77}$ and the surface coverage. ${ }^{123}$

Perhaps the most debated topic is the nature of the interaction between AFPs and ice. The adsorption-inhibition model implicitly assumes that binding is irreversible, but this view has met considerable skepticism. ${ }^{107-111,115}$ Conflicting experimental results heat the debate: some
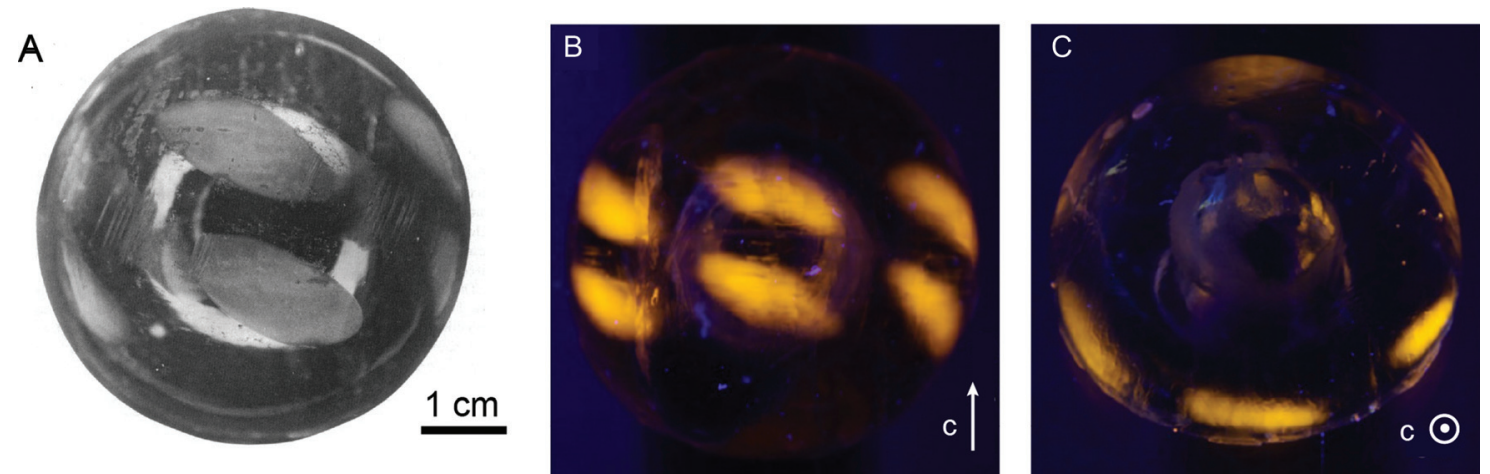

FIG. 10. Determination of the ice-binding plane specificity of IBPs. (a) Ice-etching and [(b) and (c)] FIPA of an ice hemisphere grown from a dilute solution of wfAFP-I reveal that the protein binds only to the pyramidal plane of ice. Images were taken $[(a)$ and (b)] parallel and (c) perpendicular to the c-axis direction. Figures adapted from Knight et al., Biophys. J. 59, 409 (1991) and Garnham et al., Proc. Natl. Acad. Sci. 108, 7363 (2011). 

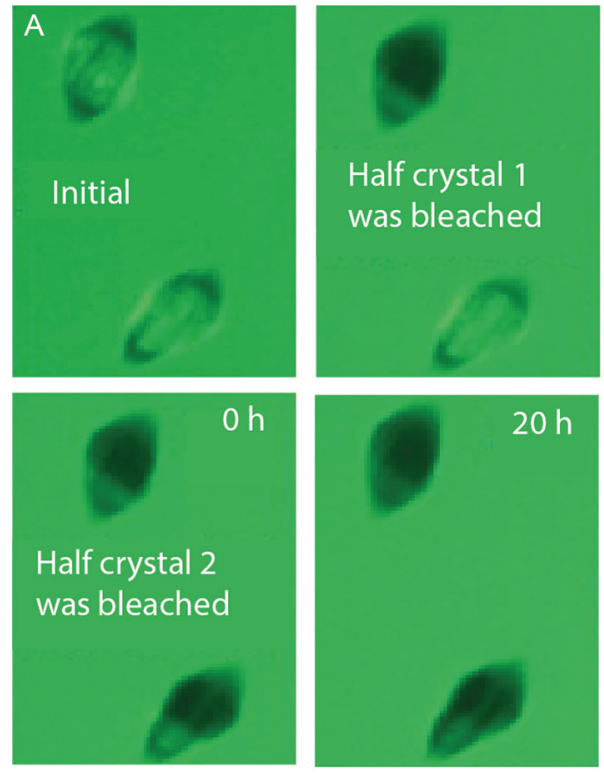

B
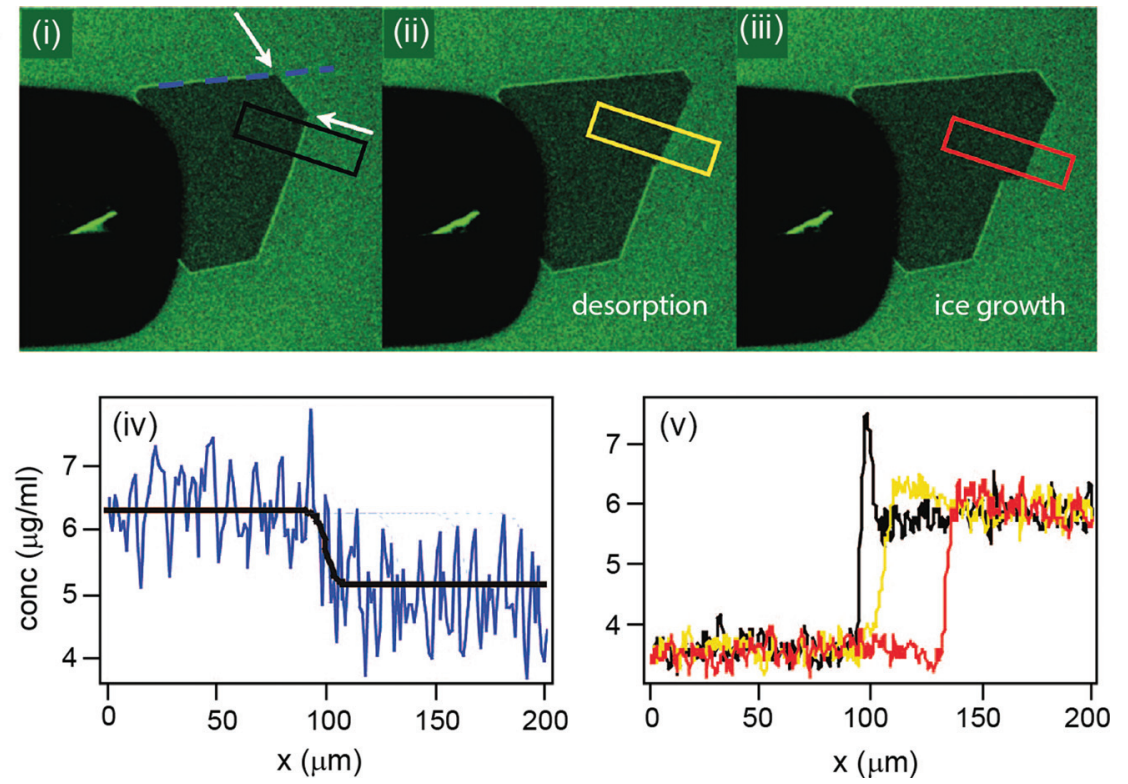

FIG. 12. Fluorescence microscopy of single ice crystals shows how IBPs bind ice. (a) Fluorescence recovery after photobleaching of opAFP-GFP bound to ice crystals reveals no exchange with the surrounding solution, suggesting the IBPs are irreversibly attached. Figure adapted from Pertaya et al., Biophys. J. 92, 3663 (2007). (b) In contrast, FITC-labeled AFGPs were found to desorb from ice crystals enabling local ice growth (i)-(iii). (iv) The fluorescence intensity profile along the ice-water interface shows a region of high fluorescence intensity due to ice-bound IBPs. (v) Similarly, bound IBPs yield a sharp rise in fluorescence intensity at $\sim 100 \mu \mathrm{m}$ in the profile across the interface (black line), which disappears upon IBP desorption followed by diffusion into the solution (yellow line). Figures adapted from Zepeda et al., Cryst. Growth Des. 8, 3666 (2008).

studies suggest binding is (partially) reversible, while others convincingly demonstrate ice-binding is irreversible. ${ }^{116-119,124}$ Fluorescence-based experiments have been employed to enable direct visualization of single ice crystals as well as the location, adsorption, and desorption of fluorescently labeled IBPs. Pertaya et al. monitored fluorescence recovery after photobleaching (FRAP) of parts of single ice crystals grown in a solution of a fusion construct of opAFP with GFP at a constant temperature of $-0.64{ }^{\circ} \mathrm{C}$ within the TH gap [Fig. 12(a)]. ${ }^{116}$ The absence of FRAP during a period as long as 7 days demonstrated the absence of exchange between the bleached IBPs on the ice crystal surface and the unbleached IBPs in solution. Contrasting with this work is a detailed study on single ice crystals kept at a temperature close to the freezing point in the presence of FITC-labeled AFGPs. Zepeda et al. observed that ice crystal growth resumes on halted faces when AFGPs desorb [Fig. 12(b)]. ${ }^{117}$ Their findings reveal a two-step inhibition mechanism comprising a reversible step that primes the surface for a subsequent stronger interaction that arrests growth. Bar et al. arrive at a similar conclusion based on a systematic study of ice-shaping and TH activity of TmAFP mutants. ${ }^{125}$

Drori et al. studied whether IBPs must be present in solution to block desorption and ice crystal growth. To this end, unbound TmAFP surrounding the ice crystal was removed, by buffer exchange in the TH gap. Neither ice crystal growth nor changes in the fluorescence intensity in solution were detected after a $20 \mathrm{~min}$ stabilization period following the depletion of the AFP [Fig. 13(a)]. ${ }^{118}$ Furthermore, the hysteresis freezing point was hardly altered: AFP depletion increased the burst growth temperature by $10 \%$. While these findings strongly suggest that TmAFP binds ice in an irreversible fashion, this may not hold for all IBPs. The behavior of opAFP differs markedly. Although bound opAFP-III seemed to remain attached to ice upon depletion of the protein from solution, AFP removal reduced the thermal hysteresis more than a factor three. ${ }^{119}$ Moreover, solvent exchange to buffer induced burst growth of the ice crystal in roughly $50 \%$ of the experiments. Fish and insect AFPs also differ in their accumulation rates. ${ }^{121}$ While adsorption of GFP-tagged opAFP-III at the prism plane reached saturation within 6 min, TmAFP-GFP accumulation on the basal plane took more than $4 \mathrm{~h}$. The fast resp. slow accumulation of prism resp. basal-plane binding AFPs also explains why TH activities of basal-plane binding IBPs increase with exposure time, while TH activities of other IBPs do not (Fig. 13). ${ }^{121}$

Without doubt, these studies will be complemented by additional experiments aiming to settle the debate on the nature of the IBP/ice interaction and its relation to IBP activity. It seems probable that it depends on both the type of IBP as well as on the environmental conditions, such as undercooling temperature, annealing time, and IBP solution concentration. Furthermore, we anticipate detailed studies on the surface coverage. ${ }^{123}$ Estimates for the mean intermolecular spacing of IBPs bound to ice are $d=21 \pm 4 \mathrm{~nm}$ for $\mathrm{c}=5 \mu \mathrm{g} / \mathrm{ml}$ AFGP4-6 solutions, ${ }^{119} d=20 \pm 5 \mathrm{~nm}$ for $c=15 \pm 5 \mu \mathrm{M}$ opAFP-III solutions, ${ }^{118} d=4-20 \mathrm{~nm}$ for $\mathrm{c}=2 \mathrm{mg} / \mathrm{ml}$ wfAFP-I solutions ${ }^{126}$ and $d=7-35 \mathrm{~nm}$ for TmAFP-GFP and $d=8-25 \mathrm{~nm}$ for opAFP-GFP solutions. ${ }^{123}$ According to the prevalent adsorption-inhibition model, these intermolecular distances on the ice crystal surface would result in far higher thermal hysteresis activities than experimentally observed. ${ }^{119,123}$ 

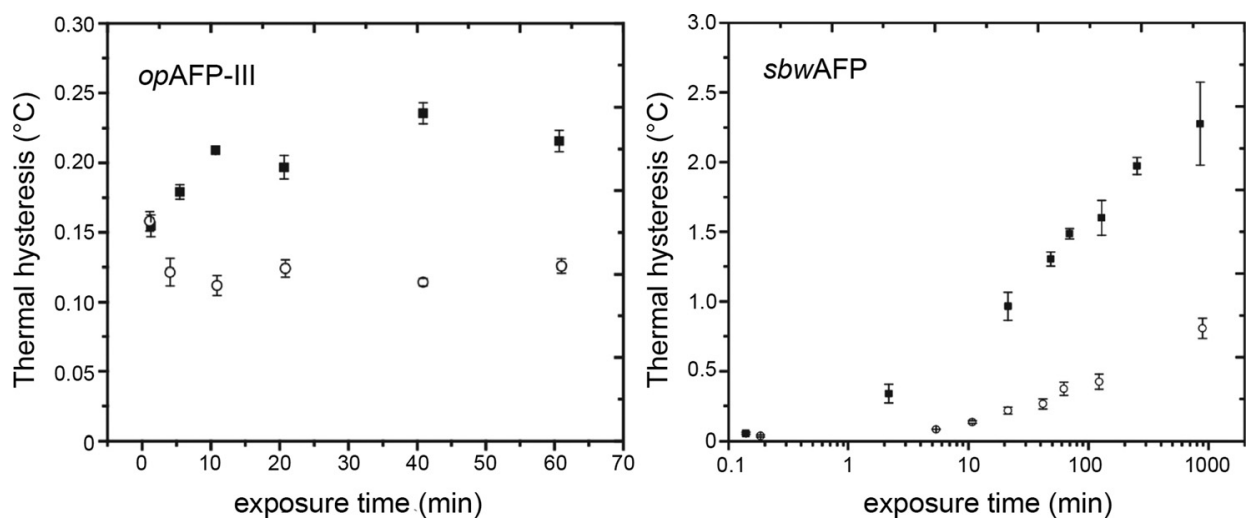

FIG. 13. Influence of exposure time to AFP solution on TH activity. (a) The TH activity of a $4 \mu \mathrm{M}$ solution of the prism plane binding opAFP-III is insensitive to the exposure time (time between formation and burst growth of the ice crystal) at $0.02{ }^{\circ} \mathrm{C}(\mathrm{O})$ and $0.1{ }^{\circ} \mathrm{C}(\mathbf{\square})$ below the melting temperature $\mathrm{T}_{\mathrm{m}}$. (b) In contrast, the activity of a $4 \mu \mathrm{M}(\bigcirc)$ and $8 \mu \mathrm{M}(\mathbf{\square})$ solution of the basal plane binding sbwAFP increases markedly with increasing exposure time.

\section{INTERACTION OF ICE BINDING PROTEINS WITH WATER}

Water molecules in the hydration layer surrounding proteins play an important role in their structure and function. ${ }^{127}$ Naturally, the hydration shell of ice-binding proteins is thought to impact their capacity to adhere to ice. The key question is how. To rationalize the observed AFP-induced freezing point depression, DeVries and coworkers proposed that AFPs immobilize or structure waters to such a large extent that it reduces the amount of bulk waters available for ice formation. ${ }^{4,5}$ However, nuclear magnetic resonance studies showed that the amount of surface-bound water is low. ${ }^{128}$ Hence, the idea of AFPs interfering with bulk waters joining the ice phase was abandoned. ${ }^{129,130}$ But, the quest to understand the physical mechanism underlying the activity of icebinding proteins continued.

\section{A. Molecular origin of ice-binding}

Initially, a hydrogen-bonding based binding mechanism was considered to be a general mode of ice-binding by IBPs. Emphasized is the importance of a good match between the ice lattice and the hydroxyl groups of Thr residues on the protein surface. ${ }^{85}$ Shortly after the first crystal structure of winter flounder AFP-I was solved, ${ }^{131}$ molecular dynamics (MD) simulations were performed in vacuum and at ice-vacuum interfaces aiming to reveal how type I $w f$ AFP binds ice. Important aspects, such as the IBP's hydration shell, were knowingly ignored or simplified. Vacuum was taken as a proxy for water, because it was too computationally expensive to perform simulations on the ice-water interface in the presence of AFPs. ${ }^{132}$ Hence, early MD studies primarily focused on the helical structure of wfAFP-I in vacuum and the docking of the spatially separated Thr residues onto the ice surface from vacuum. ${ }^{133}$

MD simulations of Cheng et al. on wfAFP-I in the presence of water pointed toward a diminished role for hydrogen bonding. The work suggested water clathrate formation near the surface of the protein due to both hydrophobic effects and hydrogen bonding resulting in a reduced solvation free energy in aqueous solution. ${ }^{134}$ Since joining two interfaces that induce clathrate formation would be energetically favorable, the effect was proposed to favor binding of AFPs onto a preorganized ice surface. Experimental evidence in support of the relevance of both hydrogen bonding and hydrophobic effects was subsequently obtained from systematic mutagenesis studies. ${ }^{68}$ This culminated in three distinct ice-binding hypotheses: (1) hydrogen-bonding groups on the IBP surface match the ice lattice oxygen atoms, (2) a flat, hydrophobic protein surface binds ice via the partitioning of hydrophobic side chains within the ice lattice, and (3) the binding site develops in a protein-assisted manner via surface-bound waters. ${ }^{135}$

\section{B. MD simulations reveal icelike hydration}

Aiming to shed light on the relevance of IBP hydration, Sharp and Madan introduced a method to quantitatively analyze changes in the water structure induced by (1) polar solutes based on the water-water hydrogen bond angle distribution function obtained from MD simulations (Fig. 14). ${ }^{136,137}$ In pure water, the distribution of the water-water H-bond angle (or tetrahedral order parameter) in the first hydration layer is bimodal, with a low- and high-angle population. The ratio of the two populations is a quantitative measure for water structural distortion due to hydrophobic or hydrophilic solutes. ${ }^{138,139}$ Sharp and coworkers used this concept to identify potential differences in the hydration structure of wild type and less active mutants of fish type I and type III AFPs. ${ }^{140-142}$ Subtle but systematic differences in the tetrahedral order parameter were found between icebinding and nonice-binding protein regions. Overall, the icebinding region has a more tetrahedral, icelike hydration within the primary hydration layer, while the nonice-binding regions are more distorted and heterogeneous. Mutant AFPs with little or no activity showed no specific tetrahedral water arrangement, suggesting that these features may underlie the molecular recognition of ice surfaces by AFPs. More recent MD simulations on fish type I and type III AFPs confirmed the earlier work of Sharp et al. ${ }^{133,143}$ A new way to quantify the tetrahedricity of the hydration water structure was introduced and compared to the previous method based on the 
A

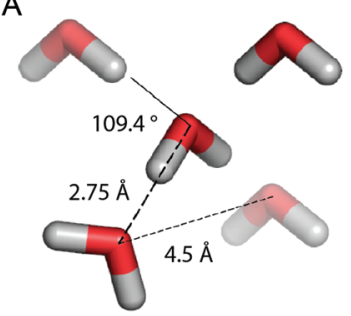

B

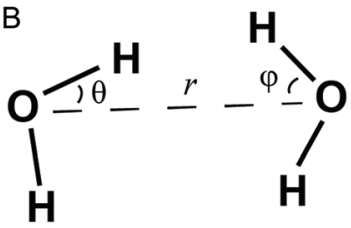

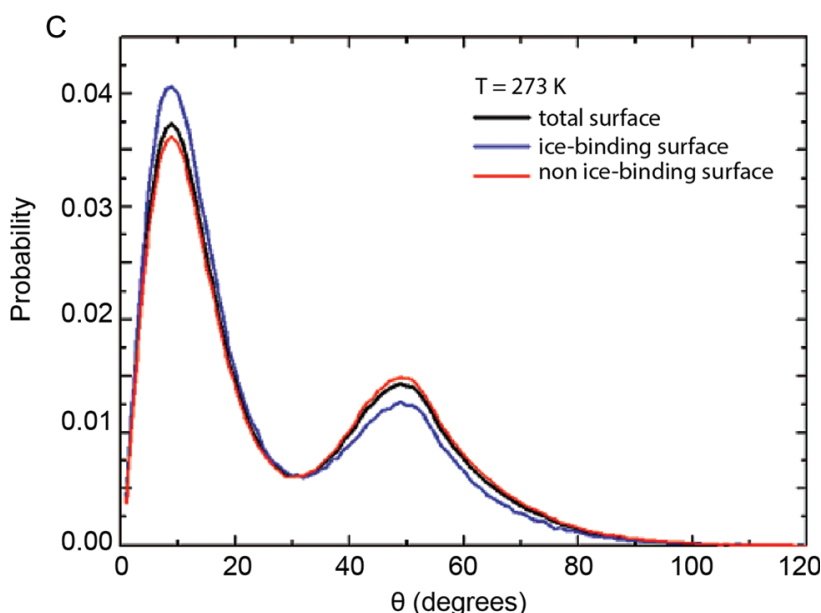

FIG. 14. Characterization of the water-water hydrogen bond (H-bond) angle distribution function in MD simulations. (a) Tetrahedral arrangement in the ice Ih lattice. (b) Geometric definitions for a water molecule pair: $r$ is the distance between the two oxygen atoms, $\theta$ is the smallest of the four H-O-O angles, $\varphi$ is the corresponding smallest $\mathrm{H}-\mathrm{O}-\mathrm{O}$ angle of the other water molecule. (c) The water-water hydrogen bond (H-bond) angle distribution function for the first hydration shell of opAFP-III. The low-angle peak corresponds to the icelike water arrangement. Figures adapted from Sharp and Vanderkooi, Acc. Chem. Res. 43, 231 (2009) and Smolin and Daggett, J. Phys. Chem. B 112, 6193 (2008).

water-water angular distribution function. ${ }^{143}$ Again, icelike waters were found on the ice-binding surface of the protein within the first hydration layer, but not beyond.

\section{Dual function of the hydration layer}

The three-dimensional structure of $\beta$-helical AFPs from insects is completely different than the native fold of type I and III AFPs. ${ }^{144}$ The x-ray diffraction crystal structure of TmAFP revealed regularly arrayed water molecules on the putative ice-binding site enclosed by structurally separated Thr-residues. ${ }^{58}$ MD simulations showed that these waters remained associated with the protein before ice binding, strongly suggesting that they are an intrinsic part of the protein and assist in ice recognition and binding. Yang et al. hypothesized that the bound waters initially facilitate ice recognition and binding, but are excluded later on during the final formation of the AFP/ice complex because it is entropically favorable and enables a better match between TmAFP and ice. ${ }^{145}$
In an insightful study, Nutt et al. put forward that the hydration layer around $\beta$-helical proteins has two functions: preconfiguration into icelike architectures on the ice-binding surface (IBS) and distortion on the non-IBS (Fig. 15). ${ }^{146}$ On the one hand, preconfigured icelike water molecules on the IBS would facilitate ice-binding by inducing ice growth in the interfacial region between ice and bulk water, which is intrinsically disordered and approximately $10-20 \AA$ thick. ${ }^{147}$ On the other hand, waters near the non-IBS would be more distorted to prevent engulfment in the ice. The authors further proposed that the high entropic gain of merging the preorganized waters at the IBS with ice through this "zipper mechanism" would sufficiently reduce the free energy of the system to result in quasi-irreversible binding.

\section{Local melting of ice}

Explicit inclusion in simulations of the interfacial region between ice and water in the presence of AFPs could reveal whether IBPs indeed impact the interfacial region, and if so,
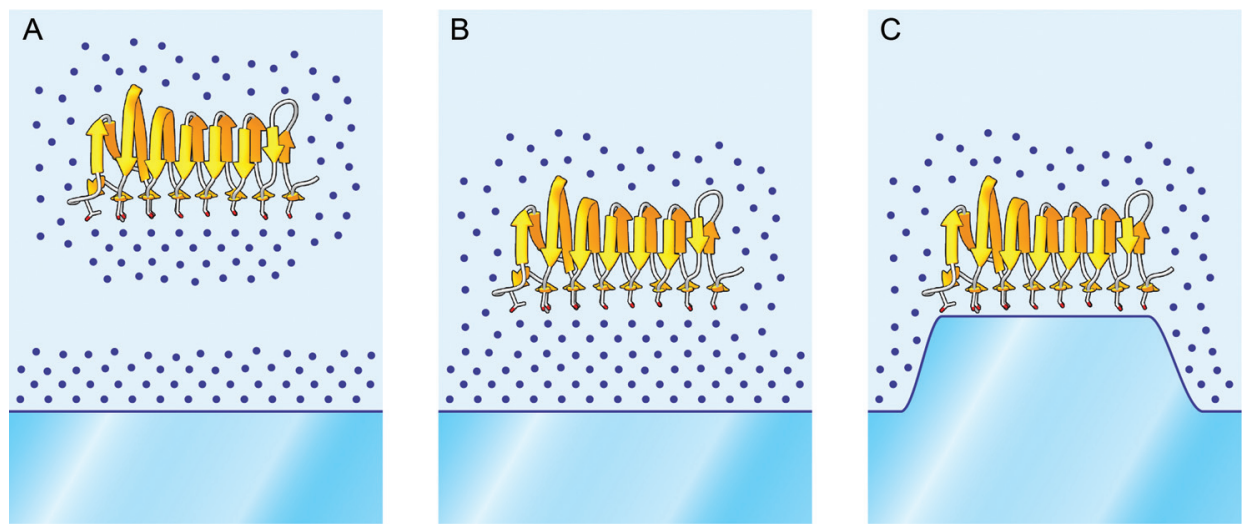

FIG. 15. Schematic representation of the proposed ice-binding mechanism by Nutt et al. (Ref. 146). (a) The AFP has ordered icelike waters at the ice-binding region, while hydration waters at the nonice-binding region are more distorted. (b) Overlap of the ordered hydration waters of the AFP with the hydration layer of the ice surface. (c) Binding of the AFP on the ice surface. Disruption of the water structure around the rest of the protein protects it from being overgrown. Figure adapted from Nutt and Smith, J. Am. Chem. Soc. 130, 13066 (2008). 
whether this relates to their differential affinity for specific ice crystal planes. Recent MD simulations by Todde et al. address the influence of $s f$ AFP and $w f$ AFP-I on the ice-water interface. ${ }^{148,149}$ Interestingly, sfAFP was found to trigger local melting of the ice surface on the nonadsorption planes (i.e., bipyramidal and prism planes), while the adsorption plane (basal plane) was found to be stable. In the simulations, a concave curvature developed on the ice front due to the partial melting of ice, which depresses the freezing temperature due to the Gibbs-Thompson effect. This model offers a possible explanation for the experimental observation of both quasipermanent and reversible binding (vide supra). ${ }^{150}$

\section{E. Bound surface waters in protein crystals}

The computational studies described in the above place the IBP hydration shell and its influence on the ice-water interfacial region at the heart of IBP activity. Experimentally, the interaction between IBPs and water can be probed by diffraction and spectroscopy. A neutron crystal structure of opAFPIII demonstrated a hydrogen bond interaction between the Thr18 residue at the IBS with a tetrahedral water cluster of four water molecules matching the primary prism plane of ice. ${ }^{151}$ The crystal structure of TmAFP displays a flat row of ordered water molecules with a spacing of $4.64 \pm 0.20 \AA$, which is guided by the arrangement of surface threonine residues and matches the ice lattice. ${ }^{58}$ Similarly, the X-ray crystal structure of the $\beta$-helical MpAFP revealed tens of bound waters on the protein surface with a good positional match to both the basal and primary prism planes of ice [Figs. 16(a) and 16(b)]. ${ }^{56}$ These and other crystal structures raised the question whether icelike waters at the IBS act as a "ligand" during ice-binding facilitating, e.g., molecular recognition or whether they are released from the protein surface resulting in an entropic gain in free energy upon ice-binding. The x-ray crystal structure of Maxi, a large type I AFP from winter flounder, shed light on this matter. It showed a dimeric, four helix bundle with the putative ice-binding residues pointing inwards, coordinating the interior waters into two intersecting polypentagonal networks [Fig. 16(c)]. ${ }^{48}$ If ice-binding of Maxi would not be mediated through these ordered waters that extend outwards, the protein would be inactive in associated form and would have to disassemble to bind ice. Sun et al. showed, however, that the chemically cross-linked IBP also shows antifreeze activity, demonstrating that Maxi does not release its ordered waters to project the ice-binding residues toward the ice surface. ${ }^{48}$ These findings strongly support an ice-binding mechanism in which IBPs preorganize water
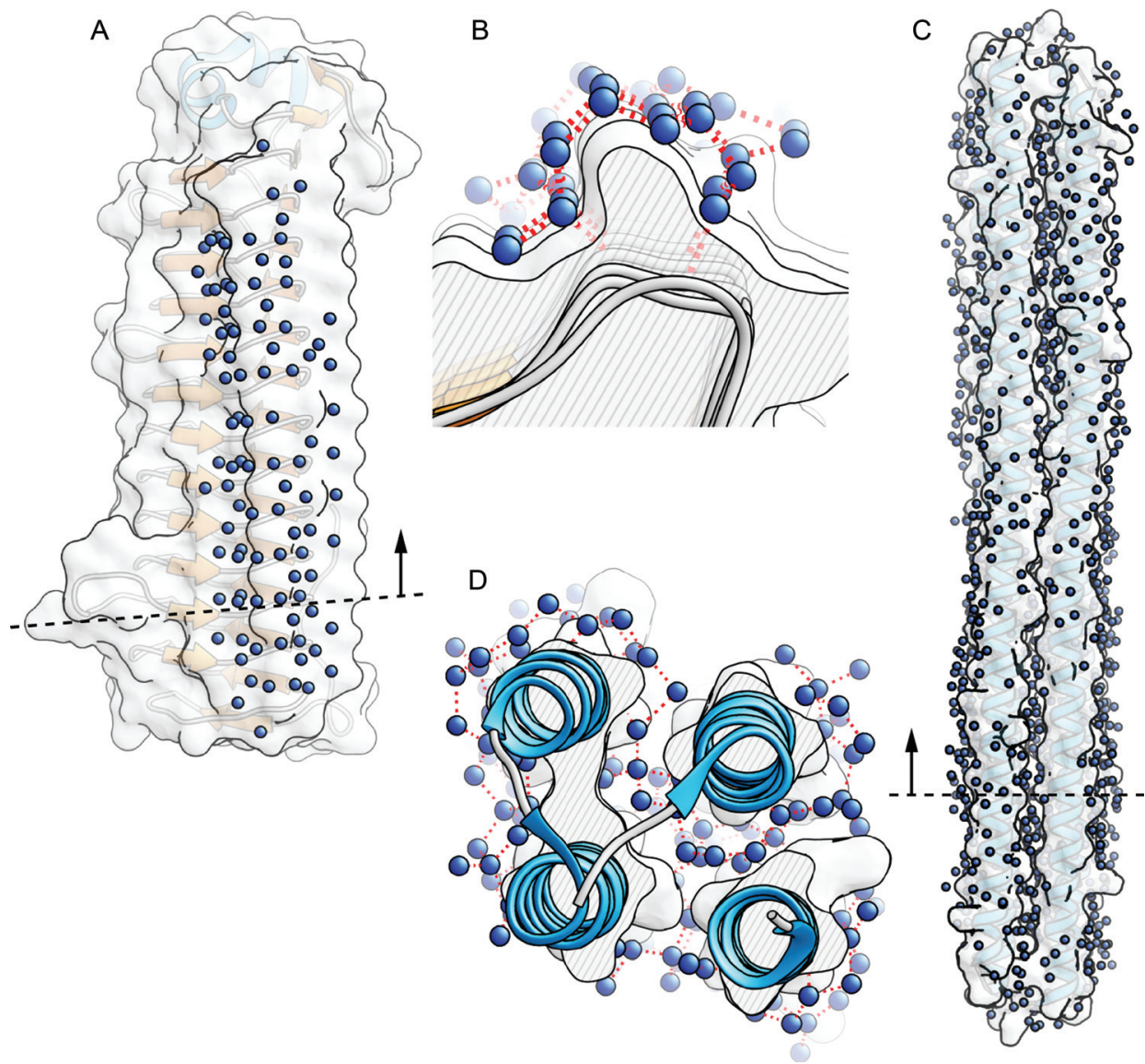

FIG. 16. Hydration waters in AFP crystal structures. Anchored clathrate waters (blue spheres) are visible on the ice-binding region of $M p$ AFP shown in topview (a) and cross-section (b). [(c) and (d)] A large type I AFP from winter flounder comprises a dimeric four helix. The putative IBS point inwards and coordinate with over 400 semiclathrate waters arranged in two intersecting polypentagonal networks extending from the interior to the exterior surface of the protein. Figures were adapted from Garnham et al., Proc. Natl. Acad. Sci. 108, 7363 (2011) and Sun et al., Science 343, 795 (2014). 
molecules within their hydration shell on the ice-binding site via which the protein is frozen onto the growing ice front. These icelike waters thus remain tightly bound throughout; they are not released from the protein surface upon binding.

\section{F. Icelike waters at the IBS in solution}

The observation of icelike waters within protein crystals motivated detailed experimental studies aiming to reveal whether or not these ordered waters are present at the icebinding site of AFPs in solution prior to adsorption onto ice. Naturally, this is a huge experimental challenge since the goal now is to probe a small amount of hydration water molecules in a vast excess of bulk water molecules.

Terahertz (THz) absorption spectroscopy was used to probe the hydration dynamics around AFPs, as well as the collective water network motions. $\mathrm{THz}$ experiments on AFGP demonstrated a considerable long-range influence on the hydration dynamics for AFGP, supposedly directly correlated to antifreeze activity. ${ }^{152}$ In a follow-up work, the antifreeze activity of $w f$ AFP-I was ascribed to a direct interaction of the AFP with ice via H-bonding of Thr-residue hydroxyl groups assisted by an extension of the dynamic hydration shell. ${ }^{153}$ Similar extended dynamical hydration shells were observed for the $\beta$-helical DAFP-1, a structural homolog of TmAFP. ${ }^{154}$ Contrasting with these experiments are ${ }^{17} \mathrm{O}$ magnetic relaxation dispersion measurements on TmAFP, which selectively monitor the rotational motion and exchange kinetics of water molecules. ${ }^{155}$ No evidence for unusual global hydration behavior of TmAFP was found.

The first hint at icelike waters within the hydration shell of IBPs in solution above freezing temperatures was apparent in the infrared spectroscopy study of Zelent $e t$ al., who attributed the absence of a vibrational frequency shift in the amide I region of AFP-I to the formation of icelike waters surrounding the ice-binding site. ${ }^{156}$ The first direct observation of icelike waters on the surface of opAFP-III above freezing temperature was reported in a collaborative work by Meister et al. The vibrational sum frequency generation (vSFG) spectrum of wild-type AFP-III showed icelike vSFG bands, which became more prominent upon lowering the temperature towards the biological working temperature regime of 0 to $-2{ }^{\circ} \mathrm{C}$ (Fig. 17). ${ }^{157} \mathrm{~A}$ single point mutation was found to eliminate both the icelike water character and the antifreeze activity. These findings clearly demonstrate the necessity of ordered icelike waters for activity, presumably since they are central to ice recognition and binding. Interestingly, vSFG experiments on DAFP-1 did not reveal such ordered icelike waters, suggesting differences exist in the molecular origin of ice-binding of the various types of IBPs. ${ }^{158}$ Future work may reveal whether this is related to the differential preferences for ice crystal planes.

\section{CONCLUSION}

In summary, cold-adopted organisms from a wide range of biological kingdoms produce ice-nucleating and icebinding proteins to control ice nucleation and growth. IBPs

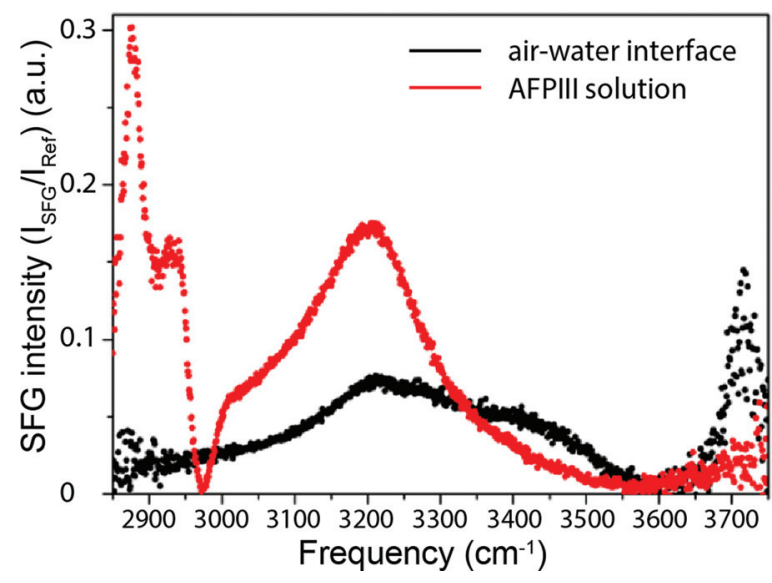

FIG. 17. Observation of ice-like waters on the protein surface of type III AFP by vSFG experiments. The vSFG spectrum of the air-water interface (black) consists of two broad bands at 3200 and $3450 \mathrm{~cm}^{-1}$ assigned to hydrogen-bonded liquid water and a sharp peak at $3700 \mathrm{~cm}^{-1}$ assigned to dangling $\mathrm{OH}$ groups sticking out of the surface. The vSFG spectrum of a opAFP-III solution (red) shows spectral features associated with the $\mathrm{CH}$ vibrations of the protein at frequencies $<3000 \mathrm{~cm}^{-1}$ and a single strong relatively narrow peak at $3200 \mathrm{~cm}^{-1}$ assigned to the response of icelike water layers associated with the ice-binding region. The icelike water peak at $3200 \mathrm{~cm}^{-1}$ was absent in the spectrum of an inactive mutant opAFP-III. Figure adapted from Meister et al., Proc. Natl. Acad. Sci. 111, 17732 (2014).

fulfill distinct functional roles, ranging from inhibition of ice growth and recrystallization to ice structuring and adhesion. The discovery in 1969 of proteins that depress the freezing point of a solution in a noncolligative manner spurred great interest across a wide range of scientific disciplines aiming to grasp and utilize ice-growth inhibition by IBPs. A plethora of IBP structures has been elucidated, showing a wide structural diversity; yet, all IBPs bind ice. On a macroscopic scale, antifreeze activity and ice plane specificity has been studied extensively. Fluorescence microscopy on fluorescently tagged IBPs greatly advanced insight into the accumulation of IBPs onto specific ice crystal planes. Computational studies revealing icelike waters at the icebinding site have been corroborated by spectroscopic and diffraction methods revealing structured waters in protein crystals as well as in solution above freezing temperatures.

Despite these major breakthroughs, the exact mechanism of growth inhibition is still under debate. Experimental and theoretical results are to be reconciled: there is a large discrepancy between AFP spacing predicted by theory and estimates obtained from microscopy and other methods. Icelike waters could be observed by spectroscopic methods for certain IBPs but were absent for others. Therefore, the concept of a unifying description for the ice binding and antifreeze activity of all classes of AFPs is questioned. Furthermore, the fundamental insights into the unique ability of IBPs to tune ice crystal growth have seen little translation into reallife applications despite promising preliminary results in frozen foods, ${ }^{14,15}$ gas hydrate inhibition, ${ }^{159-161}$ and the cryopreservation of cells, tissues, and organs. ${ }^{16} \mathrm{We}$ foresee novel insights from single-molecule techniques aiming to 
probe the interaction of individual IBPs with ice, as well as systematic studies of ice nucleation and the relation between the various functional roles of IBPs and INPs. A "computational microscope" could offer additional insight at the molecular level-especially concerning IBP hydration and the ice-water interfacial region, provided that realistic water models appropriate for ice, water, and hydration water become available. ${ }^{150} \mathrm{We}$ also anticipate a growing interest in biomimetic antifreezes for use in biomedicine, food technology, cosmetics, coating technology, de- and anti-icing strategies, and other material science applications. In summary, we look forward to a bright future for fundamental and applied research into IBPs and their synthetic mimics.

\section{NOMENCLATURE}

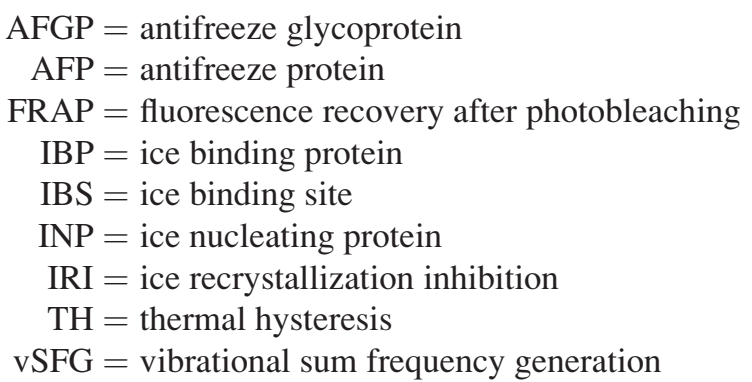

\section{ACKNOWLEDGMENTS}

The authors thank Koen Pieterse of the ICMS Animation Studio for the illustrations. This work was financially supported by the European Union (FP7-PEOPLE-2012-ITN SOMATAI Contract No. 316866 and ERC-2014-StG Contract No. 635928), the Dutch Science Foundation (NWO VENI Grant No. 700.10.406), and the Dutch Ministry of Education, Culture and Science (Gravity Program 024.001.035).

${ }^{1}$ J. G. Duman, J. Exp. Biol. 217, 820 (2014).

${ }^{2}$ P. Scholander, L. Van Dam, J. Kanwisher, H. Hammel, and M. Gordon, J. Cell. Comp. Physiol. 49, 5 (1957).

${ }^{3}$ A. L. DeVries and D. E. Wohlschlag, Science 163, 1073 (1969).

${ }^{4}$ A. L. DeVries, S. K. Komatsu, and R. E. Feeney, J. Biol. Chem. 245, 2901 (1970), available at http://www.jbc.org/content/245/11/2901.short.

${ }^{5}$ A. L. DeVries, Science 172, 1152 (1971).

${ }^{6} \mathrm{M}$. Bayer-Giraldi, I. Weikusat, H. Besir, and G. Dieckmann, Cryobiology 63, 210 (2011)

${ }^{7}$ J. A. Raymond, Proc. Natl. Acad. Sci. 108, E198 (2011).

${ }^{8}$ C. Sidebottom et al., Nature 406, 256 (2000).

${ }^{9}$ M. Hassas-Roudsari and H. D. Goff, Food Res. Int. 46, 425 (2012).

${ }^{10}$ S. Guo, C. P. Garnham, J. C. Whitney, L. A. Graham, and P. L. Davies, PloS One 7, e48805 (2012).

${ }^{11}$ T. D. Vance, L. L. Olijve, R. L. Campbell, I. K. Voets, P. L. Davies, and S. Guo, Biosci. Rep. 34, 357 (2014).

${ }^{12}$ K. E. Zachariassen and E. Kristiansen, Cryobiology 41, 257 (2000).

${ }^{13}$ J. G. Duman, Annu. Rev. Physiol. 63, 327 (2001).

${ }^{14}$ G. Petzold and J. Aguilera, Food Biophys. 4, 378 (2009).

${ }^{15}$ A. Regand and H. Goff, J. Dairy Sci. 89, 49 (2006).

${ }^{16}$ G. Amir, B. Rubinsky, L. Horowitz, L. Miller, J. Leor, Y. Kassif, D. Mishaly, A. K. Smolinsky, and J. Lavee, Ann. Thorac. Surg. 77, 1648 (2004).

${ }^{17}$ L. A. Graham, Y.-C. Liou, V. K. Walker, and P. L. Davies, Nature 388, 727 (1997)
${ }^{18}$ J. A. Gilbert, P. L. Davies, and J. Laybourn-Parry, FEMS Microbiol. Lett. 245, 67 (2005).

${ }^{19}$ C. B. Marshall, G. L. Fletcher, and P. L. Davies, Nature 429, 153 (2004).

${ }^{20}$ J. A. Raymond, C. Fritsen, and K. Shen, FEMS Microbiol. Ecol. 61, 214 (2007).

${ }^{21}$ M. J. Kuiper, C. Lankin, S. Y. Gauthier, V. K. Walker, and P. L. Davies, Biochem. Biophys. Res. Commun. 300, 645 (2003).

${ }^{22}$ L. A. Graham and P. L. Davies, Science 310, 461 (2005).

${ }^{23}$ C. B. Marshall, A. Chakrabartty, and P. L. Davies, J. Biol. Chem. 280, 17920 (2005).

${ }^{24}$ Y. Celik, L. A. Graham, Y.-F. Mok, M. Bar, P. L. Davies, and I. Braslavsky, Proc. Natl. Acad. Sci. 107, 5423 (2010).

${ }^{25}$ J. G. Duman, J. Exp. Biol. 218, 1846 (2015).

${ }^{26}$ K. E. Zachariassen and J. A. Husby, Nature 298, 865 (1982).

${ }^{27}$ J. Bale, Philos. Trans. R. Soc. B: Biol. Sci. 357, 849 (2002).

${ }^{28}$ A. Parody-Morreale, K. P. Murphy, E. Di Cera, R. Fall, A. L. DeVries, and S. J. Gill, Nature 333, 782 (1988).

${ }^{29}$ T. Olsen and J. Duman, J. Comp. Physiol. B 167, 105 (1997).

${ }^{30}$ J. Duman, J. Comp. Physiol. B 172, 163 (2002).

${ }^{31}$ M. Griffith and M. W. Yaish, Trends Plant Sci. 9, 399 (2004).

${ }^{32}$ R. S. Pearce, Ann. Bot. 87, 417 (2001).

${ }^{33}$ L. R. Maki, E. L. Galyan, M.-M. Chang-Chien, and D. R. Caldwell, Appl. Microbiol. 28, 456 (1974), available at http://www.ncbi.nlm.nih. gov/pmc/articles/PMC186742/.

${ }^{34}$ D. Gurian-Sherman and S. E. Lindow, FASEB J. 7, 1338 (1993).

${ }^{35}$ E. Marentes, M. Griffith, A. Mlynarz, and R. A. Brush, Physiol. Plant. 87, 499 (1993).

${ }^{36}$ M. Smallwood et al., Biochem. J. 340, 385 (1999).

${ }^{37}$ S. O. Yu, A. Brown, A. J. Middleton, M. M. Tomczak, V. K. Walker, and P. L. Davies, Cryobiology 61, 327 (2010).

${ }^{38}$ C. A. Knight and J. G. Duman, Cryobiology 23, 256 (1986).

${ }^{39}$ C. Krembs, H. Eicken, and J. W. Deming, Proc. Natl. Acad. Sci. 108, 3653 (2011).

${ }^{40}$ J. A. Raymond, M. G. Janech, and C. H. Fritsen, J. Phycol. 45, 130 (2009).

${ }^{41}$ P. L. Davies, Trends Biochem. Sci. 39, 548 (2014).

${ }^{42}$ G. L. Fletcher, C. L. Hew, and P. L. Davies, Annu. Rev. Physiol. 63, 359 (2001).

${ }^{43}$ L. Chen, A. L. DeVries, and C.-H. C. Cheng, Proc. Natl. Acad. Sci. 94, 3817 (1997).

${ }^{44}$ L. A. Graham, W. Qin, S. C. Lougheed, P. L. Davies, and V. K. Walker, J. Mol. Evol. 64, 387 (2007).

${ }^{45}$ V. Haridas and S. Naik, RSC Adv. 3, 14199 (2013).

${ }^{46}$ M. M. Harding, P. I. Anderberg, and A. D. J. Haymet, Eur. J. Biochem. 270, 1381 (2003)

${ }^{47}$ F. Sicheri and D. Yang, Nature 375, 427 (1995).

${ }^{48}$ T. Sun, F.-H. Lin, R. L. Campbell, J. S. Allingham, and P. L. Davies, Science 343, 795 (2014).

${ }^{49}$ Z. Jia, C. I. DeLuca, H. Chao, and P. L. Davies, Nature 384, 285 (1996).

${ }^{50}$ Y. Nishimiya, H. Kondo, M. Takamichi, H. Sugimoto, M. Suzuki, A. Miura, and S. Tsuda, J. Mol. Biol. 382, 734 (2008).

${ }^{51}$ Y. Liu, Z. Li, Q. Lin, J. Kosinski, J. Seetharaman, J. Bujnicki, J. Sivaraman, and C. Hew, PLoS One 2, e548 (2007).

${ }^{52}$ K. V. Ewart, D. S. Yang, V. S. Ananthanarayanan, G. L. Fletcher, and C. L. Hew, J. Biol. Chem. 271, 16627 (1996).

${ }^{53}$ A. A. Antson, D. J. Smith, D. I. Roper, S. Lewis, L. S. D. Caves, C. S. Verma, S. L. Buckley, P. J. Lillford, and R. E. Hubbard, J. Mol. Biol. 305, 875 (2001).

${ }^{54}$ X.-M. Li, K.-Y. Trinh, C. L. Hew, B. Buettner, J. Baenziger, and P. L. Davies, J. Biol. Chem. 260, 12904 (1985), available at http:// www.jbc.org/content/260/24/12904.long.

${ }^{55}$ S. Y. Gauthier, A. J. Scotter, F.-H. Lin, J. Baardsnes, G. L. Fletcher, and P. L. Davies, Cryobiology 57, 292 (2008).

${ }^{56}$ C. P. Garnham, R. L. Campbell, and P. L. Davies, Proc. Natl. Acad. Sci. 108, 7363 (2011).

${ }^{57}$ E. K. Leinala, P. L. Davies, D. Doucet, M. G. Tyshenko, V. K. Walker, and Z. Jia, J. Biol. Chem. 277, 33349 (2002).

${ }^{58}$ Y.-C. Liou, A. Tocilj, P. L. Davies, and Z. Jia, Nature 406, 322 (2000).

${ }^{59}$ Y. Hanada, Y. Nishimiya, A. Miura, S. Tsuda, and H. Kondo, FEBS J. 281, 3576 (2014). 
${ }^{60}$ H. Kondo, Y. Hanada, H. Sugimoto, T. Hoshino, C. P. Garnham, P. L. Davies, and S. Tsuda, Proc. Natl. Acad. Sci. 109, 9360 (2012).

${ }^{61}$ J. H. Lee, A. K. Park, H. Do, K. S. Park, S. H. Moh, Y. M. Chi, and H. J. Kim, J. Biol. Chem. 287, 11460 (2012).

${ }^{62}$ A. Hakim, J. B. Nguyen, K. Basu, D. F. Zhu, D. Thakral, P. L. Davies, F. J. Isaacs, Y. Modis, and W. Meng, J. Biol. Chem. 288, 12295 (2013).

${ }^{63}$ B. L. Pentelute, Z. P. Gates, V. Tereshko, J. L. Dashnau, J. M. Vanderkooi, A. A. Kossiakoff, and S. B. Kent, J. Am. Chem. Soc. 130, 9695 (2008).

${ }^{64}$ Z. Li, Q. Lin, D. S. C. Yang, K. V. Ewart, and C. L. Hew, Biochemistry 43, 14547 (2004)

${ }^{65}$ A. J. Middleton, C. B. Marshall, F. Faucher, M. Bar-Dolev, I. Braslavsky, R. L. Campbell, V. K. Walker, and P. L. Davies, J. Mol. Biol. 416, 713 (2012).

${ }^{66}$ A. J. Middleton, A. M. Brown, P. L. Davies, and V. K. Walker, FEBS Lett. 583, 815 (2009).

${ }^{67}$ C. P. Garnham, A. Natarajan, A. J. Middleton, M. J. Kuiper, I. Braslavsky, and P. L. Davies, Biochemistry 49, 9063 (2010).

${ }^{68}$ J. Baardsnes, L. H. Kondejewski, R. S. Hodges, H. Chao, C. Kay, and P. L. Davies, FEBS Lett. 463, 87 (1999).

${ }^{69}$ A. D. J. Haymet, L. G. Ward, M. M. Harding, and C. A. Knight, FEBS Lett. 430, 301 (1998).

${ }^{70}$ E. K. Leinala, P. L. Davies, and Z. Jia, Structure 10, 619 (2002).

${ }^{71}$ E. Kristiansen and K. E. Zachariassen, Cryobiology 51, 262 (2005).

${ }^{72}$ E. Kristiansen, S. A. Pedersen, and K. E. Zachariassen, Cryobiology 57, $122(2008)$

${ }^{73}$ N. Li, C. A. Andorfer, and J. G. Duman, J. Exp. Biol. 201, 2243 (1998), available at http://jeb.biologists.org/content/201/15/2243.long.

${ }^{74}$ D. W. Wu and J. G. Duman, J. Comp. Physiol. B 161, 279 (1991).

${ }^{75}$ I. Braslavsky and R. Drori, J. Visualized Exp. e4189 (2013).

${ }^{76}$ M. Takamichi, Y. Nishimiya, A. Miura, and S. Tsuda, FEBS J. 274, 6469 (2007).

${ }^{77}$ R. Drori, Y. Celik, P. L. Davies, and I. Braslavsky, J. R. Soc. Interface 11, 20140526 (2014).

${ }^{78}$ A. Gaede-Koehler, A. Kreider, P. Canfield, M. Kleemeier, and I. Grunwald, Anal. Chem. 84, 10229 (2012).

${ }^{79}$ N. Zaritzky, "Physical-chemical principles in freezing," in Handbook of Frozen Food Processing and Packaging 2 (CRC, Boca Raton, 2006).

${ }^{80}$ C. Budke et al., Cryst. Growth Des. 14, 4285 (2014).

${ }^{81}$ C. J. Capicciotti, J. D. R. Kurach, T. R. Turner, R. S. Mancini, J. P. Acker, and R. N. Ben, Sci. Rep. 5, 1 (2015).

${ }^{82}$ J. A. Raymond and C. H. Fritsen, Cryobiology 43, 63 (2001).

${ }^{83}$ C. A. Knight, J. Hallett, and A. L. DeVries, Cryobiology 25, 55 (1988).

${ }^{84}$ H. D. Goff, "Foods at Subzero Temperatures," in Soft materials: structure and dynamics, edited by J. R. Dutcher and A. G. Marangoni (Marcel Dekker, NY, 2005), pp. 299-320.

${ }^{85}$ C. Knight, C. Cheng, and A. DeVries, Biophys. J. 59, 409 (1991).

${ }^{86} \mathrm{~S}$. Abraham, K. Keillor, C. J. Capicciotti, G. E. Perley-Robertson, J. W. Keillor, and R. N. Ben, Cryst. Growth Des. 15, 5034 (2015).

${ }^{87}$ M. I. Gibson, C. A. Barker, S. G. Spain, L. Albertin, and N. R. Cameron, Biomacromolecules 10, 328 (2009).

${ }^{88}$ T. Hagiwara, R. W. Hartel, and S. Matsukawa, Food Biophys. 1, 74 (2006).

${ }^{89}$ C. Budke, C. Heggemann, M. Koch, N. Sewald, and T. Koop, J. Phys. Chem. B 113, 2865 (2009).

${ }^{90}$ A. J. Scotter, C. B. Marshall, L. A. Graham, J. A. Gilbert, C. P. Garnham, and P. L. Davies, Cryobiology 53, 229 (2006).

${ }^{91}$ B. Wathen, M. Kuiper, V. Walker, and Z. C. Jia, J. Am. Chem. Soc. 125, 729 (2003).

${ }^{92}$ C. S. Strom, X. Y. Liu, and Z. C. Jia, J. Am. Chem. Soc. 127, 428 (2005).

${ }^{93}$ C. S. Strom, X. Y. Liu, and Z. C. Jia, Biophys. J. 89, 2618 (2005).

${ }^{94}$ M. Bar-Dolev, Y. Celik, J. S. Wettlaufer, P. L. Davies, and I. Braslavsky, J. R. Soc. Interface 9, 3249 (2012).

${ }^{95}$ G. Vali and E. Stansbury, Can. J. Phys. 44, 477 (1966).

${ }^{96}$ G. Vali, Am. J. Phys. 39, 1125 (1971).

${ }^{97}$ G. Vali, Atmos. Chem. Phys. 14, 5271 (2014).

${ }^{98}$ C. Budke and T. Koop, Atmos. Meas. Tech. 8, 689 (2015).

${ }^{99}$ C. A. Knight, A. Wierzbicki, R. A. Laursen, and W. Zhang, Cryst. Growth Des. 1, 429 (2001)

${ }^{100}$ K. Basu, C. P. Garnham, Y. Nishimiya, S. Tsuda, I. Braslavsky, and P. Davies, JoVE (Journal of Visualized Experiments) e51185 (2014).

${ }^{101}$ J. A. Raymond and A. L. DeVries, Proc. Natl. Acad. Sci. 74, 2589 (1977).
${ }^{102}$ J. J. De Yoreo and P. G. Vekilov, "Principles of crystal nucleation and growth," in Biomineralization, edited by P. M. Dove, J. J. DeYoreo, and S. Weiner (Mineralogical Society of America, Chantilly, 2003), pp. 57-93.

${ }^{103}$ C. A. Knight, A. L. DeVries, and L. D. Oolman, Nature 308, 295 (1984).

${ }^{104}$ C. A. Knight and A. Wierzbicki, Cryst. Growth Des. 1, 439 (2001).

${ }^{105}$ D. Y. Wen and R. A. Laursen, Biophys. J. 63, 1659 (1992).

${ }^{106}$ P. W. Wilson, Cryobiology 31, 406 (1994).

${ }^{107}$ T. S. Burcham, D. T. Osuga, Y. Yeh, and R. E. Feeney, J. Biol. Chem. 261, 6390 (1986), available at http://www.jbc.org/content/261/14/ 6390.short.

${ }^{108}$ Ö. Can and N. B. Holland, J. Colloid Interface Sci. 329, 24 (2009).

${ }^{109}$ Q. Z. Li, Y. Yeh, J. J. Liu, R. E. Feeney, and V. V. Krishnan, J. Chem. Phys. 124, 204702 (2006)

${ }^{110}$ Q. Z. Li and L. F. Luo, Chem. Phys. Lett. 320, 335 (2000).

${ }^{111}$ J. J. Liu and Q. Z. Li, Chem. Phys. Lett. 378, 238 (2003).

${ }^{112}$ Q. Li and L. Luo, Chem. Phys. Lett. 216, 453 (1993).

${ }^{113}$ Q. Li and L. Luo, Chem. Phys. Lett. 223, 181 (1994).

${ }^{114}$ M. R. Anklam and A. Firoozabadi, J. Chem. Phys. 123 (2005).

${ }^{115}$ D. G. Hall and A. Lips, Langmuir 15, 1905 (1999).

${ }^{116}$ N. Pertaya, C. B. Marshall, C. L. DiPrinzio, L. Wilen, E. S. Thomson, J. Wettlaufer, P. L. Davies, and I. Braslavsky, Biophys. J. 92, 3663 (2007).

${ }^{117}$ S. Zepeda, E. Yokoyama, Y. Uda, C. Katagiri, and Y. Furukawa, Cryst. Growth Des. 8, 3666 (2008).

${ }^{118}$ Y. Celik, R. Drori, N. Pertaya-Braun, A. Altan, T. Barton, M. Bar-Dolev, A. Groisman, P. L. Davies, and I. Braslavsky, Proc. Natl. Acad. Sci. 110, 1309 (2013).

${ }^{119}$ R. Drori, P. L. Davies, and I. Braslavsky, Langmuir 31, 5805 (2015).

${ }^{120}$ C. A. Knight and A. L. DeVries, Science 245, 505 (1989).

${ }^{121}$ R. Drori, Y. Celik, P. L. Davies, and I. Braslavsky, J. R. Soc. Interface 11, 1 (2014).

${ }^{122}$ C. A. Knight and A. L. DeVries, Phys. Chem. Chem. Phys. 11, 5749 (2009).

${ }^{123}$ R. Drori, P. L. Davies, and I. Braslavsky, RSC Adv. 5, 7848 (2015).

${ }^{124}$ Y. Ba, J. Wongskhaluang, and J. B. Li, J. Am. Chem. Soc. 125, 330 (2003).

${ }^{125}$ M. Bar, Y. Celik, D. Fass, and I. Braslavsky, Cryst. Growth Des. 8, 2954 (2008).

${ }^{126} \mathrm{~S}$. Grandum, A. Yabe, K. Nakagomi, M. Tanaka, T. Fumio, Y. Kobayashi, and P.-E. Frivik, J. Cryst. Growth 205, 382 (1999).

${ }^{127}$ P. Ball, Chem. Rev. 108, 74 (2008).

${ }^{128}$ A. Haschemeyer, W. Guschlbauer, and A. L. DeVries, Nature 269, 87 (1977).

${ }^{129}$ A. DeVries, Philos. Trans. R. Soc. London B 304, 575 (1984).

${ }^{130}$ R. Feeney, T. Burcham, and Y. Yeh, Annu. Rev. Biophys. Biophys. Chem. 15, 59 (1986).

${ }^{131}$ D. Yang, M. Sax, A. Chakrabartty, and C. Hew, Nature 333, 232 (1988).

${ }^{132}$ P. Dalal, J. Knickelbein, A. D. Haymet, F. D. Sönnichsen, and J. D. Madura, PhysChemComm 4, 32 (2001).

${ }^{133}$ A. Wierzbicki, P. Dalal, T. E. Cheatham, J. E. Knickelbein, A. Haymet, and J. D. Madura, Biophys. J. 93, 1442 (2007).

${ }^{134}$ A. Cheng and K. M. Merz, Jr., Biophys. J. 73, 2851 (1997).

${ }^{135}$ J. D. Madura, K. Baran, and A. Wierzbicki, J. Mol. Recognit. 13, 101 (2000).

${ }^{136}$ B. Madan and K. Sharp, J. Phys. Chem. 100, 7713 (1996).

${ }^{137}$ K. A. Sharp and B. Madan, J. Phys. Chem. B 101, 4343 (1997).

${ }^{138}$ K. R. Gallagher and K. A. Sharp, J. Am. Chem. Soc. 125, 9853 (2003).

${ }^{139}$ K. A. Sharp and J. M. Vanderkooi, Acc. Chem. Res. 43, 231 (2010).

${ }^{140}$ K. R. Gallagher and K. A. Sharp, Biophys. Chem. 105, 195 (2003).

${ }^{141}$ C. Yang and K. A. Sharp, Biophys. Chem. 109, 137 (2004).

${ }^{142}$ C. Yang and K. A. Sharp, Proteins: Struct., Funct., Bioinf. 59, 266 (2005).

${ }^{143}$ N. Smolin and V. Daggett, J. Phys. Chem. B 112, 6193 (2008).

${ }^{144}$ S. P. Graether and B. D. Sykes, Eur. J. Biochem. 271, 3285 (2004).

${ }^{145}$ Z. Yang, Y. Zhou, K. Liu, Y. Cheng, R. Liu, G. Chen, and Z. Jia, Biophys. J. 85, 2599 (2003).

${ }^{146}$ D. R. Nutt and J. C. Smith, J. Am. Chem. Soc. 130, 13066 (2008).

${ }^{147}$ J. A. Hayward and A. Haymet, J. Chem. Phys. 114, 3713 (2001).

${ }^{148}$ G. Todde, C. Whitman, S. Hovmoüller, and A. Laaksonen, J. Phys. Chem. B 118, 13527 (2014). 
${ }^{149}$ G. Todde, S. Hovmoüller, and A. Laaksonen, J. Phys. Chem. B 119, 3407 (2015).

${ }^{150}$ M. Calvaresi, S. Hoüfinger, and F. Zerbetto, Biomacromolecules 13, 2046 (2012).

${ }^{151}$ E. I. Howard et al., J. Mol. Recognit. 24, 724 (2011).

${ }^{152}$ S. Ebbinghaus, K. Meister, B. Born, A. L. DeVries, M. Gruebele, and M. Havenith, J. Am. Chem. Soc. 132, 12210 (2010).

${ }^{153}$ S. Ebbinghaus, K. Meister, M. B. Prigozhin, A. L. DeVries, M. Havenith, J. Dzubiella, and M. Gruebele, Biophys. J. 103, L20 (2012).

${ }^{154}$ K. Meister, S. Ebbinghaus, Y. Xu, J. G. Duman, A. DeVries, M. Gruebele, D. M. Leitner, and M. Havenith, Proc. Natl. Acad. Sci. 110, 1617 (2013).

${ }^{155}$ K. Modig, J. Qvist, C. B. Marshall, P. L. Davies, and B. Halle, Phys. Chem. Chem. Phys. 12, 10189 (2010).
${ }^{156}$ B. Zelent, M. A. Bryan, K. A. Sharp, and J. M. Vanderkooi, Biophys. Chem. 141, 222 (2009).

${ }^{157}$ K. Meister, S. Strazdaite, A. L. DeVries, S. Lotze, L. L. Olijve, I. K. Voets, and H. J. Bakker, Proc. Natl. Acad. Sci. 111, 17732 (2014).

${ }^{158}$ K. Meister, S. Lotze, L. L. Olijve, A. L. DeVries, J. G. Duman, I. K. Voets, and H. J. Bakker, J. Phys. Chem. Lett. 6, 1162 (2015).

${ }^{159}$ C. M. Perfeldt, P. C. Chua, N. Daraboina, D. Friis, E. Kristiansen, H. Ramlov, J. M. Woodley, M. A. Kelland, and N. von Solms, Energy Fuels 28, 3666 (2014)

${ }^{160}$ H. Sharifi, V. K. Walker, J. Ripmeester, and P. Englezos, Energy Fuels 28, 3712 (2014).

${ }^{161}$ D. Tonelli, C. J. Capicciotti, M. Doshi, and R. N. Ben, RSC Adv. 5, 21728 (2015). 